OPEN ACCESS

Edited by:

Fabiola Castro,

University of São Paulo, Brazil

Reviewed by:

Elisabeth Littwitz-Salomon,

University Hospital Essen, Germany Michael Brown,

Duke University, United States

*Correspondence:

Tiago da Silva Medina

tiago.medina@accamargo.org.br

Specialty section:

This article was submitted to Cytokines and Soluble Mediators in Immunity, a section of the journal

Frontiers in Immunology

Received: 24 September 2021 Accepted: 15 November 2021 Published: 02 December 2021

Citation:

Vitiello GAF, Ferreira WAS, Cordeiro de Lima VC and Medina TS (2021) Antiviral Responses in Cancer: Boosting Antitumor Immunity Through Activation of Interferon Pathway in the Tumor Microenvironment.

Front. Immunol. 12:782852. doi: 10.3389/fimmu.2021.782852

\section{Antiviral Responses in Cancer: Boosting Antitumor Immunity Through Activation of Interferon Pathway in the Tumor Microenvironment}

\author{
Glauco Akelinghton Freire Vitiello ${ }^{1}$, Wallax Augusto Silva Ferreira ${ }^{1,2}$, \\ Vladmir Cláudio Cordeiro de Lima $^{3}$ and Tiago da Silva Medina ${ }^{1,4 *}$ \\ 1 Translational Immuno-Oncology Group, International Research Center, A.C. Camargo Cancer Center, São Paulo, Brazil, \\ ${ }^{2}$ Laboratory of Cytogenomics and Environmental Mutagenesis, Environment Section (SAMAM), Evandro Chagas Institute, \\ Ananindeua, Brazil, ${ }^{3}$ Department of Clinical Oncology, A.C. Camargo Cancer Center, São Paulo, Brazil, ${ }^{4}$ National Institute of \\ Science and Technology in Oncogenomics and Therapeutic Innovation, São Paulo, Brazil
}

In recent years, it became apparent that cancers either associated with viral infections or aberrantly expressing endogenous retroviral elements (EREs) are more immunogenic, exhibiting an intense intra-tumor immune cell infiltration characterized by a robust cytolytic apparatus. On the other hand, epigenetic regulation of EREs is crucial to maintain steadystate conditions and cell homeostasis. In line with this, epigenetic disruptions within steady-state cells can lead to cancer development and trigger the release of EREs into the cytoplasmic compartment. As such, detection of viral molecules by intracellular innate immune sensors leads to the production of type I and type III interferons that act to induce an antiviral state, thus restraining viral replication. This knowledge has recently gained momentum due to the possibility of triggering intratumoral activation of interferon responses, which could be used as an adjuvant to elicit strong anti-tumor immune responses that ultimately lead to a cascade of cytokine production. Accordingly, several therapeutic approaches are currently being tested using this rationale to improve responses to cancer immunotherapies. In this review, we discuss the immune mechanisms operating in viral infections, show evidence that exogenous viruses and endogenous retroviruses in cancer may enhance tumor immunogenicity, dissect the epigenetic control of EREs, and point to interferon pathway activation in the tumor milieu as a promising molecular predictive marker and immunotherapy target. Finally, we briefly discuss current strategies to modulate these responses within tumor tissues, including the clinical use of innate immune receptor agonists and DNA demethylating agents.

Keywords: antiviral immune response, antitumor immunity, oncolytic viruses, interferons, epigenetic regulation, endogenous retroviral elements, immunotherapy 


\section{INTRODUCTION}

Better understanding of the immune mechanisms operating in human cancers has led to breakthroughs in the way many cancers are treated with the introduction of effective immunotherapies, particularly those based on immune checkpoint blockade (ICB) (1). However, the therapeutic value of these approaches is still to be proven for many cancers, and even in cancer types showing high response rates to ICB, a significant proportion of patients may fail to respond to the treatment, highlighting the need of further investigation in order to enhance the treatment efficacy and broaden the application of this promising therapeutic approach (2).

Predictive biomarkers of immunotherapy response currently in use include the tumor expression of immune checkpoints, tumor mutational burden (TMB) and, to some extent, the density of tumor infiltrating lymphocytes (TILs) (3). While the expression of immune checkpoints indicates that ICB targets are active in the tumor milieu, TMB and TILs are correlates of tumor immunogenicity, reflecting the abundance of neoepitopes available for adaptive immunity recognition and the existence of active immune responses (3). Tumors with higher TMB and/ or TILs, such as melanoma and lung cancers, the so-called "hot" tumors, are more likely to respond to immunotherapy (4). Conversely, current immunotherapies fail to elicit efficient antitumor immune responses in patients harboring "cold" tumors, including breast and prostate cancers $(4,5)$.

Despite this, these biomarkers do not reflect the tumor complexity and their clinical utility varies largely among different cancer types, making the search for global predictive biomarkers for ICB an attractive field (2). Also, the existence of cold tumors and the incapacity of ICB to elicit strong antitumor responses in this context highlight the need to investigate therapeutic strategies that may act as adjuvants to trigger or strengthen anti-tumoral immune response against poorly immunogenic cancers. Of note, the absence of strong innate immunity stimulators and the preponderance of autoantigens in tumor cells are factors associated with the inability to properly activate anti-tumor immune responses in these cancers (6).

Viruses are the most abundant and perhaps the most ancient biological entities in the world. These organisms need to infect cells to replicate and have evolved several mechanisms to store and propagate their genetic information. They are broadly divided into DNA and RNA viruses, the latter being further subdivided into retroviruses and single-stranded or doublestranded RNA viruses (6). Several viruses have the ability to infect human cells, and some of them can transform normal cells in multiple ways, such as through the induction of cellular proliferation and insertional mutagenesis, thus triggering cancer development and progression (7).

Among the major cancer-associated viruses are Epstein-Barr Virus (EBV), Human Papillomavirus (HPV), Hepatitis C virus (HCV), Hepatitis B virus (HBV) and Merkel cell polyomavirus (MCV) (7). Other viruses, such as Mouse Mammary Tumor Virus (MMTV) (8) and human cytomegalovirus (HCMV) (9), have debatable associations with human cancer development and could influence disease onset and progression, although no strong causal relationship has been shown.

Notwithstanding, some viruses and viral elements have been incorporated into the cellular genomes of different organisms over the course of evolution, probably due to infection in germinative cells. These reminiscent sequences, which make up about $40 \%$ of the human genome, are called endogenous retroviral elements (EREs), and their expression is tightly regulated by epigenetic mechanisms, to avoid the genomic instability they may cause through new insertional events (10, 11). Indeed, when this control is lost, EREs become aberrantly expressed and new insertional events lead to cancer initiation and progression by promoting genomic instability and driving evolution of transformed cells in multiple ways (12).

Interestingly, recent evidence suggests that tumor cells expressing viral elements or cancers aberrantly expressing EREs are more immunogenic and show increased TILs and cytotoxicity scores (13). Mechanistically, their replication intermediates are recognized by innate immunity sensors, enhancing the inflammatory response in the tumor microenvironment (TME), mainly through the induction of interferon (IFN) responses (13). Additionally, translated proteins from viruses and EREs might be presented via class I MHC on tumor cells and activate adaptive immune responses $(14,15)$.

Altogether, these data indicate that antiviral immune responses might boost antitumor immunity and may assist the discovery of biomarkers or therapeutic targets that can enhance immunotherapy response. Indeed, several therapeutic strategies aimed to induce a "viral mimicry" state in tumor cells are being investigated and have shown promising results in preclinical models and clinical trials, including DNA demethylating agents and agonists of innate immunity sensors $(16,17)$.

Thus, in this review, we discuss how viral elements or analogs can activate intra-tumoral immune responses mediated by IFNs and might serve as biomarkers and/or adjuvants for immunotherapies. We first summarize the immune response to viruses, discussing the activation of innate immune receptors that ultimately promotes IFN responses and activation of adaptive immunity; we next discuss the clinical meaning of interferon activation in tumors and the impact of cancer-associated viruses and EREs in the tumor immune microenvironment; finally, we present therapeutic approaches employing this knowledge to boost antitumor immune responses that are currently under development and clinical testing.

\section{ACTIVATION OF IFN SIGNALING BY VIRUSES}

Viruses elicit strong innate immune responses through activation of different families of pathogen recognition receptors (PRRs), including toll-like receptors (TLR), localized in plasma or endosomal membranes, and several cytoplasmic receptors that function as sensors for viral DNA (e.g. cGAS) and RNA (e.g. RIG-I and MDA-5). These receptors act through different, but convergent signaling cascades, culminating in the 
activation of transcription factors (TFs) that coordinate the expression of pro-inflammatory cytokines, including the expression of IL- $1 \alpha$, IL- $1 \beta$, IL-18, IL- 6 and TNF $\alpha$ via NF- $\kappa B$ activation and the expression of type I and type III IFNs, through the activation of interferon response factors (IRFs), mainly IRF3 and IRF7 (Figure 1) (18-21).

Type I IFNs (IFN-I) include the IFN $\alpha$ subfamily (which include 13 related proteins in humans), IFN $\beta$, IFNe, IFNא and IFN $\omega$, of which IFN $\alpha$ and IFN $\beta$ are the most prominent cytokines (22). Type III IFNs (IFN-III) include three closelyrelated IFN- $\lambda$, namely IFN- $\lambda 1$, IFN- $\lambda 2$ and IFN- $\lambda 3$, previously known as IL-29, IL-28A and IL-28B, respectively $(22,23)$. Type I and type III interferons act through different pairs of class II cytokine receptors, triggering similar intracellular pathways that share the same final effector TFs to induce the so-called antiviral state within infected or susceptible cells (24). This mechanism prevents or restrains viral infection and replication through the induction of cytostasis and apoptosis, upregulation of the antigen-presenting machinery, expression of viral restriction factors, and recruitment and activation of immune cells (25).

Plasma membrane TLRs, such as TLR2 and TLR4, may respond to viral infections, since viral molecules, including surface proteins or glycoproteins, were shown to activate these receptors during viral adsorption and budding (18). However, antiviral innate immunity is commonly triggered when viral nucleic acids are recognized by endosomal TLRs, such as double stranded RNA (dsRNA) recognition by TLR3, single-stranded RNA (ssRNA) recognition by TLR7 and TLR8, or unmethylated CpG motifs by TLR9 $(18,19)$ (Figure 1).

Except for TLR3, all TLRs can recruit MyD88 when activated (TLR2 and TLR4 recruit the TIRAP adaptor protein before MyD88). MyD88 then interacts with IL-1R-associated kinase (IRAK)-1, -2 and -4 , and phosphorylated IRAK1 interacts with and activates the ubiquitin ligase TNFR-associated factor 6 (TRAF6). TRAF6-mediated K63 polyubiquitination activates a series of kinases, including TGF- $\beta$-activated kinase 1 (TAK1) and IKB-kinase complex (IKK), which phosphorylate and mark $\mathrm{I} \kappa \mathrm{B}$ for degradation, thus releasing $\mathrm{NF}-\kappa \mathrm{B}$ for nuclear translocation. TAK1 and IKK also activate the Mitogenactivated protein kinase (MAPK) pathway and other TFs, such as Interferon Response Factor 5 (IRF5) and AP-1, which also interact with NF- $\mathrm{KB}(26)$. Altogether, these TFs coordinate the expression of pro-inflammatory cytokines such as IL-6, TNF $\alpha$, IL-1 $\beta$ and IL-18, but not of IFNs (20) (Figure 1).

TLR3, otherwise, recruits TIR-domain containing adapterinducing interferon- $\beta$ (TRIF), which directly recruits and

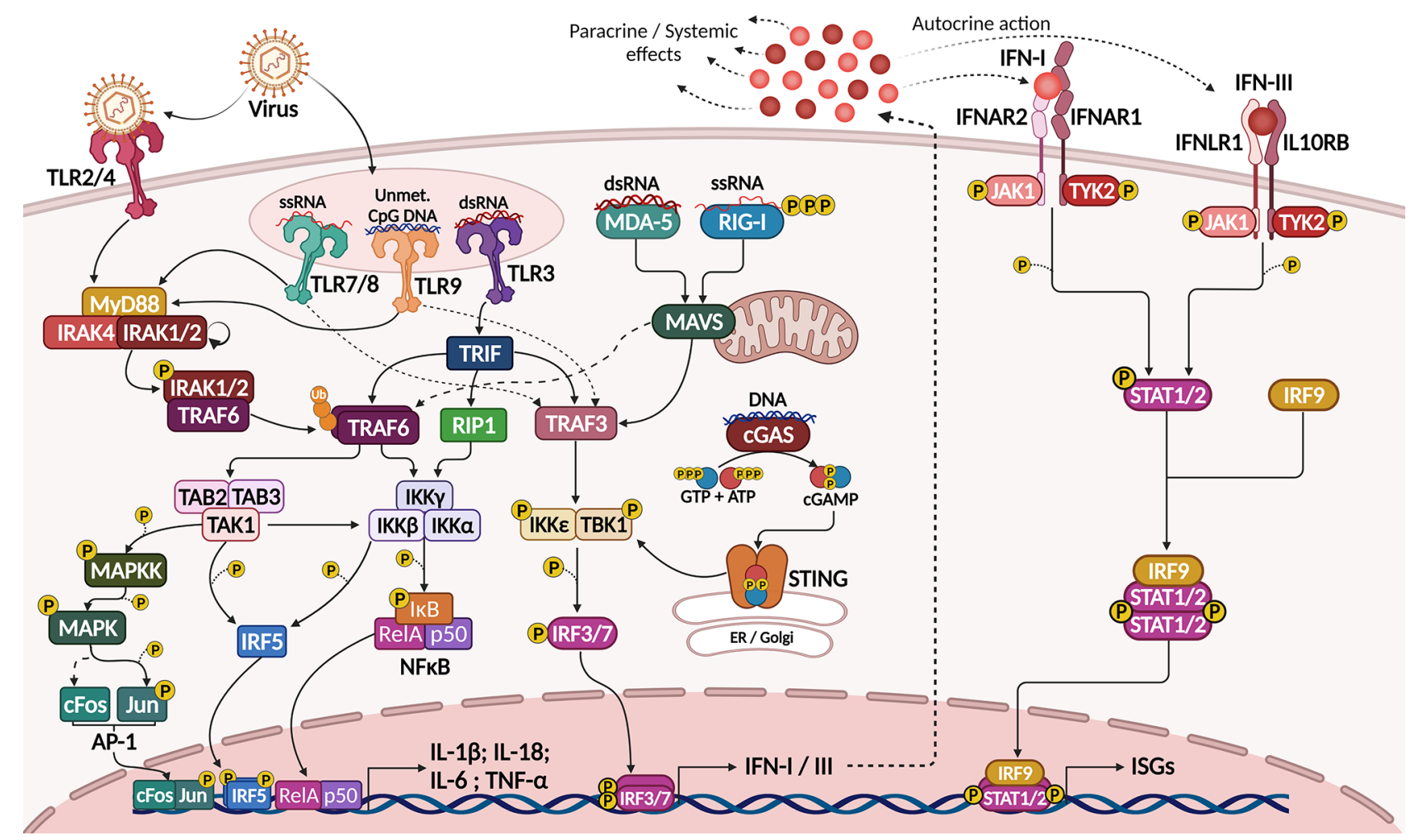

FIGURE 1 | Activation of IFN-I/III response by viral sensing through PRRs. Sensing of viral molecules by plasma membrane (TRL4), endosomal (TLR3, 7, 8 and 9) or cytosolic (RLRs and cGAS) PRRs activate signaling pathways culminating in the expression of pro-inflammatory cytokines (IL-1 $\beta$, IL-6, IL-18 and TNF $\alpha$ ) by NF- $\kappa B$, AP-1 and IRF5 transcription factors and of IFN-I and IFN-III by IRF3 and IRF7 (left). IFNs act though transmembrane receptors to activate STAT1, STAT2 and IRF9. This complex then translocates to the nucleus to govern the expression of several interferon-stimulated genes (right), which mediate an antiviral state leading to cell apoptosis, cytostasis, antigen presentation and expression of viral restricting factors. Created with BioRender.com. 
activates TRAF6 and the receptor-interacting protein 1 (RIP1), resulting in more potent $\mathrm{NF}-\mathrm{\kappa B}$ activation and proinflammatory cytokine production. TRIF also activates TRAF3, and this ubiquitin ligase is capable of activating TBK1 and IKKi kinases, which then activate IRF3 (20). Other TLRs, such as TLR7 and TLR9, also activate TRAF3 in response to viral nucleic acids in the endosome, but the main TF activated in this context is IRF7. Both IRF3 and IRF7 coordinate the expression of type I and type III interferons, being critical regulators of antiviral immune responses $(18,20)$ (Figure 1).

More recently it became clear that besides transmembrane TLRs, cytoplasmic proteins can act as virus sensors and elicit type I interferon responses. These include DNA sensors, such as cGAS, and RNA sensors, such as RIG-I, MDA-5 and LGP-2, collectively called RIG-like receptors (RLRs) (21). Also, AIM-2 and NLRP3 cytoplasmic proteins were shown to recognize intracellular DNA and dsRNA, respectively, being capable of activating the inflammasome complex to produce bioactive IL$1 \beta$ and IL-18, further stimulating inflammation and the activation of immune cells (18). Several other proteins may act as sensors or accessory proteins in the recognition of viral nucleic acids in different contexts, but their role in antiviral immune responses is less clearly understood (18).

Different RNA sensors recognize RNA molecules differently depending on the RNA nature, and this also reflects how they recognize different viruses. RIG-I was shown to bind mainly 5'triphosphate ssRNAs and short (up to $1 \mathrm{~kb}$ ) dsRNA, while MDA5 recognizes long ( $>2 \mathrm{~kb}$ ) dsRNAs preferentially (18). Both proteins have a C-terminal RNA-interacting domain, an RNA helicase domain, and two N-terminal caspase activation and recruitment domains (CARD), required for signaling. LGP-2 lacks the CARD domain, and a regulatory role was proposed for this protein; however, more recent evidence has shown that LGP2 might potentiate RIG-I and MDA-5 responses to viral RNAs (27).

Upon RNA recognition, the CARD domains of RIG-I or MDA-5 are exposed, favoring the oligomerization of these proteins. Their CARD domain then interacts with the CARD domain from MAVS (also called IPS-1), a mitochondrialocalized adaptor protein that forms aggregates and interacts with both TRAF3 and TRADD, thus recruiting TRAF6. TRAF3 then activates TBK1 and IKK€ to induce IRF3/7 activity, while TRAF6 activates the IKK complex to promote NF- $\kappa B$ nuclear translocation and activity (18) (Figure 1).

Regarding recognition of cytoplasmic DNA, cGAS (an acronym for cyclic-di-GMP-AMP (cGAMP) synthase) is an enzyme that, when bound to DNA, synthesizes the second messenger cGAMP from GTP and ATP (28). This mediator then binds to STING, located in the endoplasmic reticulum (ER) membrane, and promotes its traffic to the Golgi complex where STING interacts with and activates the IKKe/TBK1 complex, also inducing the activation of IRF3/7 (Figure 1). Besides recognizing DNA from viruses, cGAS signaling can also be activated by RNA:cDNA hybrids generated during viral replication in the cytoplasm (29).

Collectively, IRF3 and IRF7 activation leads to the expression of type I and type III IFNs, which are secreted by infected cells and exert autocrine and paracrine signaling through the activation of transmembrane receptors: IFNAR1/IFNAR2 dimers for type I IFNs and IFNLR1/IL10RB dimers for type III IFNs. Both receptor dimers act through the JAK-STAT pathway, activating the receptor-associated kinases JAK1 and TYK2, which in turn activate STAT1, STAT2 and IRF9 (30). These TFs then translocate to the nucleus and regulate the expression of a plethora of genes, collectively known as interferon stimulated genes (ISGs), after binding to specific DNA sequences known as interferon-sensitive response elements (ISRE) (22) (Figure 1).

There are currently hundreds of well-defined ISGs and probably thousands of genes that are directly or indirectly regulated by IFNs (25). These genes include several viral restriction factors that act in different phases of viral replication, including fusion to the cellular and endocytic membrane, genome replication and protein translation, and are responsible to induce an antiviral cellular state, which is associated with enhanced proteasomal function, enhanced autophagy, cytostasis, apoptosis and improved antigen presentation through the upregulation of the antigenpresenting machinery in target cells (25).

Despite acting through similar molecular pathways and showing great overlap in the core genes they activate, IFN-I and IFN-III may differ in their physiological roles and spatiotemporal dynamics during antiviral responses. Overall, IFN-III responses act mainly in anatomical barriers, such as epithelial cells in mucosal surfaces that are in constant contact with pathogens, exerting their roles in a paracrine manner. IFNIII is deemed to evoke an initial, controlled, weaker and sustained response, whereas IFN-I emerges later and shows an acute and intense pattern of activation, stimulating more ISGs than IFN-III $(30,31)$. Factors explaining these differences include the restricted expression of IFNLR1 in epithelial cells, the ligandreceptor binding kinetics (32) and the differential activation of STAT-independent pathways in target cells (33), which are only beginning to be appreciated (30).

In addition to its effects on target cells, IFN signaling affects immune cells in multiple ways. IFN-I was shown to induce the production of chemokines (e.g., CXCL9, CXCL10 and CCL2), which enhance lymphocyte and macrophage recruitment, and cytokines (e.g., IL-15), that promote the maintenance of memory $\mathrm{CD}^{+} \mathrm{T}$ cells and natural killer (NK) cells (34). IFN-I also supports the differentiation of monocytes into dendritic cells (DC) and stimulates DC maturation by upregulating MHC-I and -II antigen-presenting machinery, costimulatory molecules, such as CD80 and CD86, and CCR7, a chemokine receptor that promotes DC migration to the T-cell zone of draining lymph nodes, where they can activate and polarize naive $\mathrm{T}$ cells into effector and/or memory T cells (34).

Upon antigen-driven activation, IFN-I has direct effects on $\mathrm{T}$ cells by favoring the polarization of naive $\mathrm{CD} 4^{+} \mathrm{T}$ cells towards the IFN $\gamma$-secreting Th1 phenotype and facilitating the activation, clonal expansion and IFN $\gamma$ secretion of cytotoxic $\mathrm{CD}^{+} \mathrm{T}$ cells. NK cell activation and IFN $\gamma$ secretion are also enhanced by IFN-I (34). In turn, IFN $\gamma$ has a major role in coordinating immune responses by inducing the IgG production by B-lymphocyte- 
derived plasma cells, boosting macrophage function and enhancing DC antigen presentation (35).

On the other hand, IFN-I signaling in the absence of TCR signaling may lead to $\mathrm{T}$ cell apoptosis $(36,37)$, while chronification of IFN-I signaling triggers immunoregulatory mechanisms aimed to avoid severe tissue injury (38). This is achieved through the induction of immunosuppressive cytokines, such as IL-10 $(39,40)$, and exhaustion receptors and ligands on immune cells, such as PD-1 (41) and PD-L1 (42), among other suppressive molecules $(43,44)$, leading to a hyporesponsive state in activated $\mathrm{T}$ cells.

Similarly, IFN-III has direct effects on many immune cell populations, although these are not fully understood due to the non-ubiquitous expression of IFNLR1 on immune cells and the controversial data found in different models of immune response $(30,31)$. Notably, plasmacytoid and conventional DCs are able to both produce and respond to IFN-III, whereas other immune cells, such as neutrophils, macrophages and NK cells, are only capable to directly respond to it, but cannot produce IFN-III themselves $(30,31,45)$.

An STAT-independent immunoregulatory role for IFN-III in neutrophils has been demonstrated in various contexts, including infectious and autoimmune diseases (30, 31, 45). DCs were shown to produce high levels of IL-12 in response to IFN-III (46). In NK cells, IFN-III was required for maximal IFN$\gamma$ production and antitumor activity (47), however it is not clear whether IFN-III has direct action on these cells (45). IFN-III has also shown to enhance IFN- $\gamma$ production and reduce Th2 cytokines in $\mathrm{CD}^{+} \mathrm{T}$ cells, favoring a Th1 pattern $(48,49)$. In $\mathrm{CD}^{+} \mathrm{T}$ cells, IFN-III was shown to improve cell expansion and cytolytic activity (50).

However, controversial effects of IFN-III on T cells are shown depending on which inflammatory context has been evaluated: IFNLR1-deficient mice showed improved $\mathrm{CD} 4^{+}$and $\mathrm{CD} 8^{+} \mathrm{T}$ cell responses to transient acute LCMV infection, but showed diminished $\mathrm{T}$ cell responses and worse disease control in a chronic infectious scenario (51). Also, much of the IFN-III effects on $\mathrm{T}$ cells are attributed to its roles in the activation of the innate immunity compartment, especially DCs, and it remains to be determined the specific effects of IFN-III on $\mathrm{T}$ cells (45).

\section{INTERFERONS IN TUMOR IMMUNITY AND THERAPEUTIC RESPONSES}

Based on what has been discussed, IFN responses may exert antitumor effects through cell-intrinsic mechanisms, such as promotion of apoptosis, as well as the activation of immune mechanisms that optimally act against tumor cells, particularly those mediated by cytotoxic NK and T cells. In chronic scenarios, IFNs induce abundant expression of exhaustion markers on immune cells that can be targeted by ICB. Of note, many factors may activate IFN responses in the TME, including genotoxic therapies and engagement of PRRs by their natural ligands or agonists (Figure 2), which are currently being exploited as potential therapeutic agents, proving the crucial anticancer roles exerted by IFNs (52).

Early studies demonstrated that IFN-I administration improves the survival of tumor-harboring mice (53) and that endogenous IFN-I was required for tumor rejection $(54,55)$. Following the promising results observed in pre-clinical models, clinical trials with IFN $\alpha$ for human cancer treatment also showed efficacy in promoting regression of many tumor types (56), leading to IFN $\alpha 2$ approval as the first anticancer immunotherapy and its clinical use for many years to treat different cancers, including hematological malignancies $(57,58)$ and melanoma $(59)$.

IFN-I activation of immune responses has shown to be an essential trigger in mediating anti-tumor activities. IFN-I-induced transcripts correlated with $\mathrm{T}$ cell infiltration in human melanoma and mice models have shown that IFN-I can be produced by intratumoral DCs upon tumor implantation, being indispensable for the accumulation of intratumor cross-presenting dendritic cells and priming of $\mathrm{CD}^{+} \mathrm{T}$ cells (60) (Figures 2, 3). Further data also suggested that IFN-I signaling has anti-metastatic properties by regulating epithelial-to-mesenchymal transition (EMT), angiogenesis, and the expression of cytokines, chemokines and their receptors in cancer (61).

The role of IFN-I in cancer immunoediting has also been elegantly demonstrated (62). Using mouse models for tumor transplantation and primary development, it was shown that non-immune-edited (immunogenic) sarcomas grown in rag2deficient mice (which lack lymphocytes) were rejected by wildtype syngeneic mice; however IFNAR1 blockade abrogated this effect. Likewise, ifnar 1 knockout mice were more susceptible to carcinogen-induced tumor formation, and tumors grown in these animals were controlled when transplanted into WT animals, similarly to tumors generated in rag2-knockout mice. Additional experiments have shown that IFN-I signaling in immune cells, but not in tumor cells, is essential for tumor elimination (62). In conclusion, these data prove that IFN-I acting on immune cells is necessary for tumor immune responses, and the absence of this stimulus creates a permissive environment that promotes the growth and progression of nonimmune-edited tumors (62).

Although the use of IFN for cancer treatment has decreased due to its related adverse effects and the advent of more effective targeted therapies, IFN-I exerts an important role in regulating cancer progression through the activation of antitumor immune responses and may serve as prognostic or therapeutic predictor biomarker in different cancers and therapeutic modalities (52). Relatedly, the efficacy of genotoxic therapies, including chemotherapy and radiotherapy, has been shown to largely rely on activation of the IFN-I pathway (63-67), while exogenous IFN-I stimulation could potentiate responses to these treatments $(65,68)$ (Figures 2, 3). Of note, the unresponsiveness of IFN-I-deficient animals was attributed to their inability to activate dendritic and $\mathrm{CD}^{+} \mathrm{T}$ cells $(52,63,66)$.

Accordingly, cGAS activation and IFN-I signaling in DCs are required for anti-tumor immune responses after radiotherapy (69) (Figure 3). Also, progression of tumor cells through cell cycling after the genotoxic stimulus led to the accumulation of 


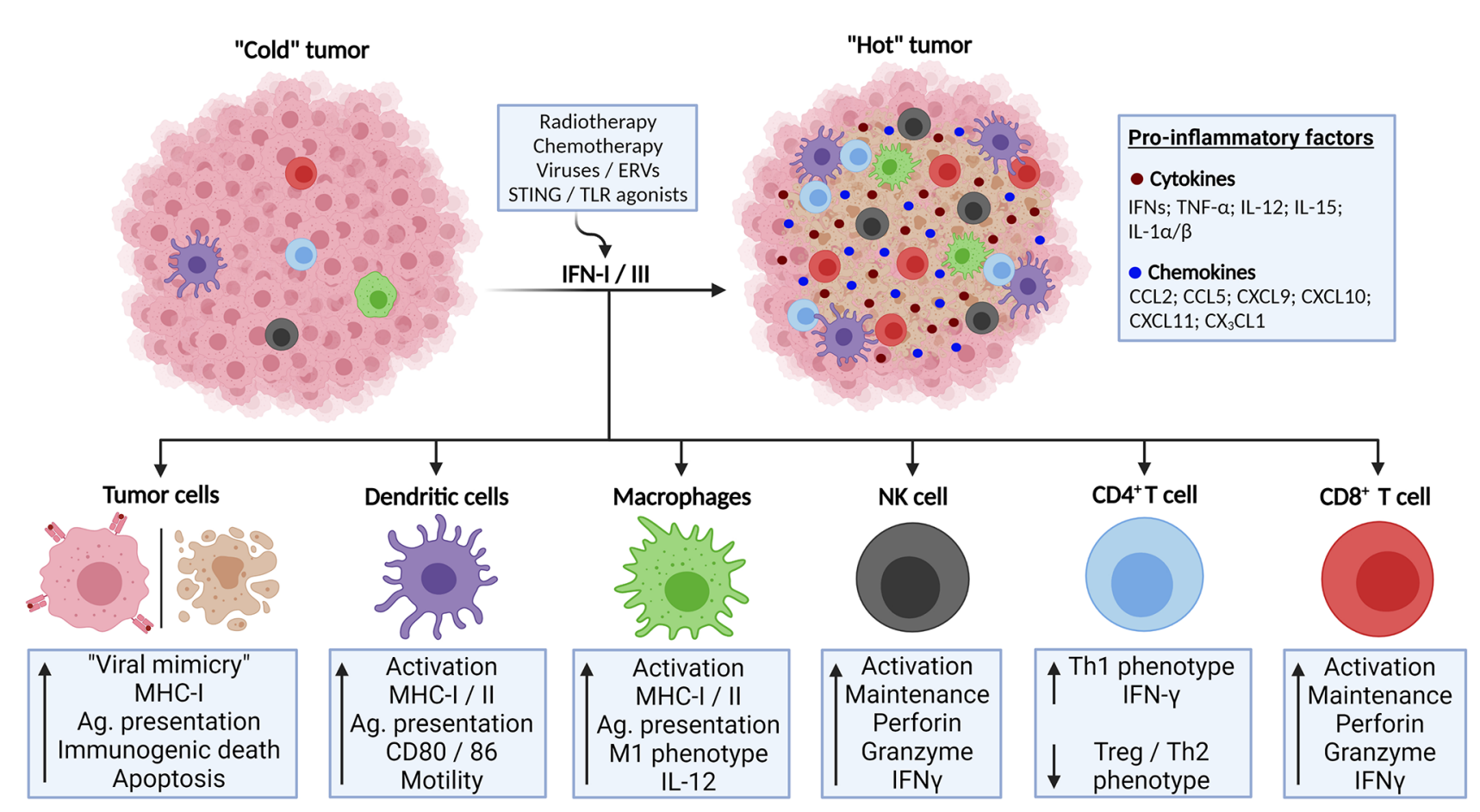

FIGURE 2 | Activation of IFN-I/III responses in TME lead to enhanced anti-tumor response and tumor control. Poorly immunogenic ("cold") tumors might be converted to highly infiltrated tumors ("hot") through the activation of IFN-1/III responses. This might be accomplished through several strategies, such as genotoxic therapies and triggering of innate immunity receptors involved in antiviral responses. IFN-//III mediate this phenomenon by its actions on tumor cells, inducing immunogenic cell death and enhanced antigen presentation as well as by its effects in activating anti-tumor immune cell populations, such as dendritic cells, $T$ lymphocytes and natural killer (NK) cells. Created with BioRender.com.

cytoplasmic micronuclei that were recognized by cGAS, leading to IFN production and $\mathrm{T}$ cell priming, indicating that beyond DCs, tumor cell sensing of damaged DNA via STING pathway also contributes to IFN-I production and cancer immune responses (70) (Figure 3). Further, IFN-I activation was necessary to the abscopal (systemic) effects of radiotherapy in disseminated cancers, a phenomenon that is highly dependent on intratumor $\mathrm{CD}^{+} \mathrm{T}$ cell priming $(70,71)$.

In contrast, IFN-I pathway activation in tumor cells was associated with radiotherapy resistance, and ifnar1-deficient tumor cells were more susceptible to $\mathrm{T}$ cell killing in mouse models (72). Conversely, IFN-I signaling in tumor cells has been shown to upregulate indoleamine-2,3-dioxygenase 1 (IDO1) after radiation, which contributed to radiation resistance and inhibition of immune responses in tumors (73). These results highlight that (i) IFN-I activities and their potential impact on radiotherapy response varies according to the TME compartment (tumor $v$ s immune cells) wherein this pathway is activated and (ii) IFN-I effects in boosting the radiotherapy response are immune-mediated.

In genotoxic chemotherapy with anthracyclines, TLR3 activation in tumor cells has been shown to largely contribute to IFN-I responses and tumor elimination after chemotherapy (66). Doxorubicin treatment induced an antiviral-like expression program, which was abrogated in Tlr3-knockout mice that did not respond to chemotherapy unless supplied with recombinant IFN $\alpha$, IFN $\beta$ or CXCL10. Furthermore, an IFN-I-related expression signature predicted response to anthracyclines in multiple breast cancer cohorts (66). Importantly, DNA damaging agents might generate dsRNA, which can be recognized by TLR3 (74), and evidence has shown that ssRNA might also stimulate TLR3 through the formation of incomplete stem-loop structures (75), providing a rationale for TLR3 activation in this context (Figure 3). Additionally, IFN-I signaling was protective against breast cancer metastization, as it was required for $\mathrm{NK}$ and $\mathrm{CD}^{+}$anti-tumor functions in this scenario (76, 77). Accordingly, pre-chemotherapy IRF9 expression was consistently associated with treatment response and improved metastasis-free survival following chemotherapy in triple-negative breast cancer (78).

Since immunotherapies also rely on the efficient priming of intratumor immune responses, IFN-I signaling could also potentiate the efficiency of ICB (79). Indeed, STING-deficient mice were unable to respond to anti-PD-1 and anti-CTLA-4 in B16F10 melanoma model, and cGAMP administration along with ICB inhibited tumor and metastasis formation and delayed tumor growth (80). This process depends on IFN-I, and endothelial cells were shown as major contributors to this phenomenon by highly producing IFN $\beta 1$ in response to cGAMP (80). In the same melanoma model, cGAS-STING pathway and IFN-I production were necessary to potentiate anti-PD-L1 response, while STING- or cGAS-deficient mice were unable to respond to this therapy (81). Further, cGAMP 


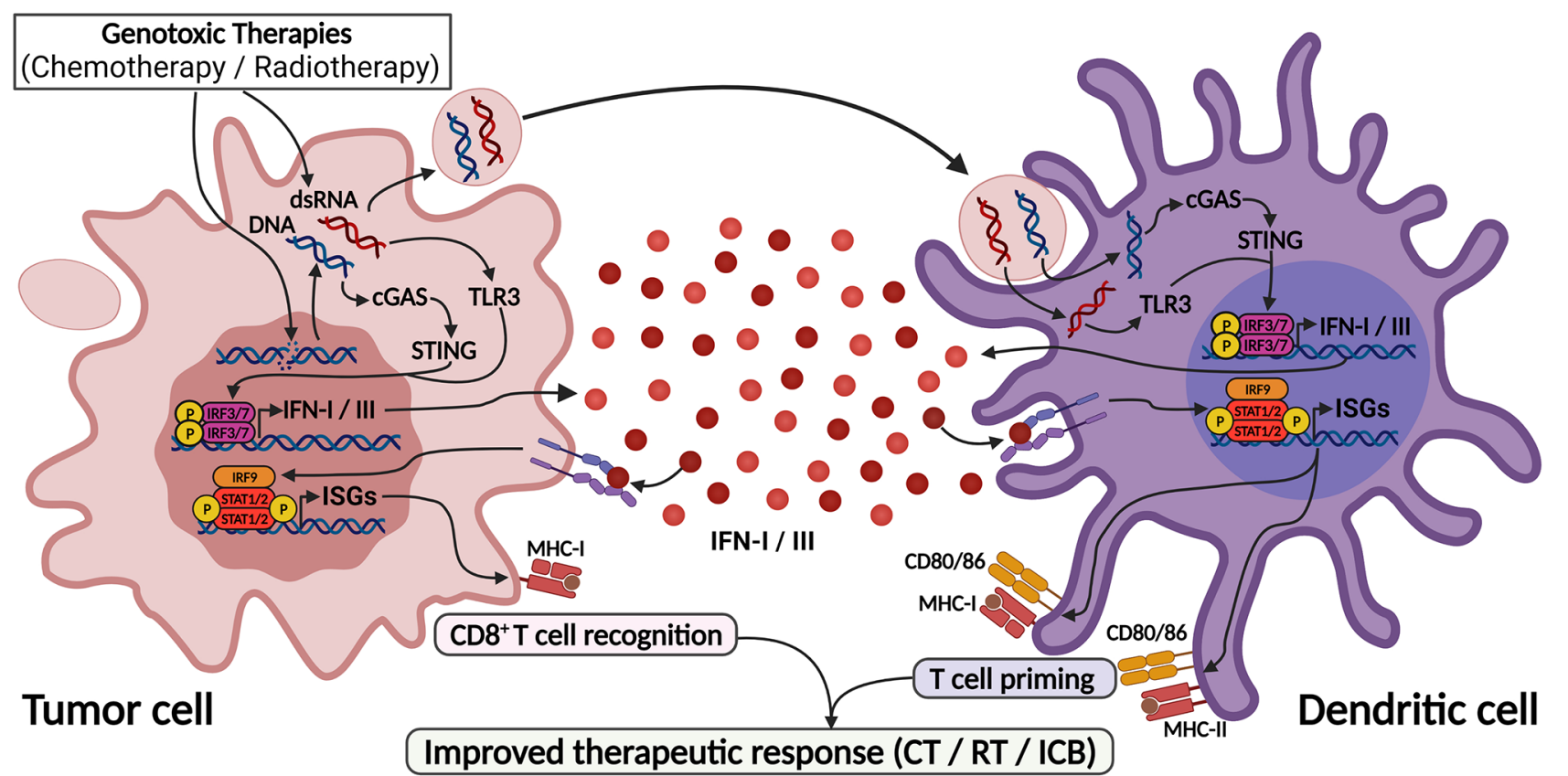

FIGURE 3 | DNA-damaging agents trigger IFN-I/III responses through activation of cGAS/STING and TLR3 pathways. DNA-damaging agents cause DNA leakage into cytoplasm as well as induce dsRNA formation, leading to the activation of cGAS and TLR3. Also, blebs from dying cell containing DNA and dsRNA are captured by dendritic cells and also sensitizes cGAS and TLR3 in these cells. These pathways culminate in IFN-I/III production by both cells, leading to efficient dendritic cell activation and T cell priming, thus enhancing anti-tumor responses. This process mediates the response to genotoxic therapies and found the base for their use as adjuvants for ICB therapies. Created with BioRender.com.

administration increased DC and antigen-specific T-cell activation in a dose-dependent manner in WT and cGASdeficient mice, but not in STING-deficient animals (81). Otherwise, the increased susceptibility of ifnar1-deficient tumor cells to $\mathrm{T}$ cell-mediated killing ultimately led to improved response to anti-PD-L1 ICB, once again highlighting the differing translational meaning of IFN-I activation in different tumor compartments (72).

Enhancement of ICB responses may be achieved by the use of genotoxic therapies before ICB, and several works have shown that the cGAS-STING-IFN-I pathway significantly contributes to this effect $(70,71,82,83)$. Cytoplasmic DNA accumulation following radiotherapy is necessary to properly activate the cGAS-STING pathway and potentiate ICB (70) (Figure 3). In line with this, it was recently shown that high radiation doses induce the exonuclease Trex1, which degrades cytoplasmic DNA and downmodulates cGAS-STING pathway, thus attenuating cancer immunogenicity; on the other hand, low dose radiotherapy (LDRT) effectively induces cytoplasmic DNA accumulation without Trexl induction, and this efficiently stimulates IFN $\beta$ production and $\mathrm{T}$-cell priming, enhancing the response to immunotherapy (83). Also, LDRT promoted immunologic infiltration in a murine lung cancer model characterized by the absence of $\mathrm{T}$ cell infiltration and induced cytotoxic $\mathrm{CD}^{+}$and $\mathrm{CD}^{+} \mathrm{T}$ cell populations (84). These findings were validated in immunotherapy-resistant human tumors, which after radiation were highly infiltrated by Th1 cell subpopulations (84).
Otherwise, recent reports have shown that prolonged IFN-I and II stimuli can upregulate and sustain the expression of multiple genes involved in T-cell exhaustion, including but not limited to $\mathrm{PD}-\mathrm{L} 1$, thus mediating resistance to immunotherapies. Sustained IFN-I signaling and IFN $\beta$ expression were also associated with resistance to anti-PD-1 blockade therapy through the induction of NOS2 in immune and tumoral compartments of melanoma, promoting an accumulation of regulatory $\mathrm{T}$ cells and myeloid cells in tumor tissues (44). Conversely, in animals that do not respond to combinatorial treatment with anti-PD1 and anti-CTLA4, pharmacological inhibition of the IFN pathway could render immunotherapyresistant tumors sensitive to either ICB monotherapy (43).

IFN-III functions in cancer are less clearly understood. The more restricted expression of IFNLR1 and IL10RB as opposed to IFNAR1 and IFNAR2 (which are ubiquitously expressed by nucleated cells) and the known attenuated inflammatory potential of IFN-III in comparison to IFN-I has led to the hypothesis that IFN-III administration would exert anti-tumor activities with less toxicity compared to IFN-I $(30,85)$. Indeed, IFN-III has shown in vitro and in vivo anti-tumor effects through the induction of tumor apoptosis and cell cycle arrest, inhibition of angiogenesis and activation of the immune compartment (86-90).

In a recent report, it has been shown that conventional dendritic cells 1 (cDC1) were responsible for type-III interferon production and that both intratumor $\mathrm{cDC} 1$ abundance and IFN-III expression were associated with 
improved prognosis in breast cancer patients (91). Further, IFNIII expression correlated with pro-inflammatory cytokines and chemokines in the tumor milieu, favoring Th1 polarization of intratumor immune responses (91). In agreement with this, in vitro stimulation of patient-derived $\mathrm{CDC} 1$ by TLR3 agonists led to the secretion of several inflammatory mediators, including IFN- $\beta$, IFN- $\gamma$, IL-12, CXCL10, CXCL11 and CX3CL1 (91). Also, IFN-III was required for optimal IFN $\gamma$ production and antitumor activity of NK cells (47). Therefore, IFN-III may also exert direct and indirect anti-tumor activities and might hold potential as a biomarker and/or therapeutic target in cancer. However, the complex biology of IFN-III including its spatio-temporally restricted expression and its multifaceted roles on the immune system and human cancers, as well as its potential adverse effects must be further understood before its clinical use.

Altogether, these results emphasize the promising roles of IFN-I/III in cancer progression and control, as well as the complex nature of the dynamic IFN responses in the TME. Besides cytotoxic therapies, it became recently clear that other stimuli can also activate interferon responses, including infection by exogenous or oncogenic viruses and expression of EREs. In addition to the activation of innate immunity programs, viral sequences may generate proteins that can be recognized by the adaptive immunity, as discussed in the next sections.

\section{EXOGENOUS VIRUSES AS TRIGGERS OF ANTI-TUMOR IMMUNE RESPONSES}

Over 50 years ago, Epstein et al. published their electron microscopy observations of EBV (Epstein-Barr virus) in cultured tumor cells of Burkitt's lymphomas, which led to the discovery of the first human oncovirus $(92,93)$. Since then, much focus has been placed on discovering novel human oncoviruses, mainly using large-scale analyses of the complex genetic architecture of tumors $(94,95)$.

According to the last survey, up to $20 \%$ of all human cancers are related to oncogenic viruses, and some are recognized as human carcinogens by the International Agency for Research on Cancer (IARC) (96-98). Currently, at least eight wellcharacterized human oncoviruses are known: (i) Epstein-Barr Virus (EBV); (ii) human papillomavirus (HPV; types 16, 18, 31, 33, 35, 39, 45, 51, 52, 56, 58, and 59); (iii) Kaposi's sarcomaassociated herpesvirus (KSHV), also known as human herpesvirus type 8 (HHV-8); (iv) human T-cell lymphotropic virus type 1 (HTLV-1); (v) Merkel cell polyomavirus (MCPyV); (vi) hepatitis $\mathrm{B}$ virus (HBV); (vii) hepatitis $\mathrm{C}$ virus ( $\mathrm{HCV})$; and (viii) human cytomegalovirus (HCMV) (97, 99-102). Of note, they exhibit a high genomic diversity, displaying either DNA (EBV, KSHV, HPV, HBV, and MCPyV) or RNA (HCV and HTLV-1) genomes. Interestingly, some viruses predominantly affect a particular gender (e.g., 90\% of HPV-induced cancers occur in females) and have a broad tissue tropism.

Accumulating evidence indicates that the presence of oncoviruses is not sufficient to induce cancer development, as only a small proportion of infected individuals eventually develop cancer. Instead, it has been proposed they contribute to a multistep tumorigenesis and are implicated in many cancer hallmarks (95, 103-105), usually involving chronic inflammation (by generating reactive oxygen (ROS) and nitrogen (RNS) species), immunosuppression (e.g., co-opt cellular processes for replication and undermine immune recognition to support their propagation), sustained proliferative capacity through the expression of viral-encoded oncogenes by the infected cells (e.g., T antigen of MCPy; LMP1, LMP2A, LMP2B, EBNA1, EBNA2 of EBV; Tax of HTLV-1; E5, E6 and E7 of HPVs), genomic instability generated by insertional mutagenesis, control of the host epigenetic machinery (106), regulation of the mitochondrial function of infected cells (107) and alteration of tumor suppressor (e.g., p53 and pRB pathways) and host signaling (e.g., PI3K-AKT-mTOR; MAPK; Notch; WNT/ $\beta$ catenin; NF- KB) pathways (7, 108, 109).

Alternatively, the "Hit-and-Run" mechanism proposes that oncoviruses may act as initial triggers for cancer development (the "hit"), and the viral genome subsequently disappears (the "run") after accumulation of new mutations in the host cell throughout carcinogenesis (110). However, clear experimental evidence is still required to support this hypothesis, although this phenomenon has been observed in an animal model (111). Interestingly, the presence of a mutational pattern consistent with off-target activity of the IFN-induced antiviral APOBEC3 cytidine deaminases in multiple human cancers (112) might constitute a link among viral infections, antiviral immunity and carcinogenesis that may operate through the hit-and-run mechanisms (113, 114). Indeed, association amongst APOBEC3 expression, mutational signature and viral infection has been established for cancers associated with HPV (115-117), polyomaviruses (118) and EBV (119). Additionally, recent work has given support to the idea that the genomic integration of some oncoviruses may be associated with increased somatic copy-number alterations and mutations (such as TP53, CDKN2A and TERT mutations in head and neck cancers) nearby the integration sites, and higher abundance of $\mathrm{T}$ cell and M1 macrophage populations in head and neck tumors (95), providing new insights into the causality of oncoviruses.

The TME plays a crucial role in modulating immune responses during cancer development, thereby influencing therapeutic outcomes and patient prognosis. In this context, several lines of evidence support that some oncoviruses that have been integrated into the genome of tumor cells might also directly or indirectly impact the intratumoral infiltration of immune cells and antitumor immunity. Table 1 summarizes the findings of studies investigating the influence of oncoviruses on intratumor immune infiltrates. Overall, virus-associated cancers had increased infiltration of immune cells, particularly $\mathrm{CD}^{+} \mathrm{T}$ cells, and the presence of oncoviruses is commonly associated with better prognosis. Also, in some cases, notably for HCC and GC, viral infections were associated with high levels of regulatory $\mathrm{T}$ cells (Table $\mathbf{1}$ ). Notwithstanding, some cancers associated with viruses, such as HPV-associated HNSCC, have increased lymphoid aggregates composed of B and T cells known as tertiary lymphoid structures $(127,129)$, which may serve as 
TABLE 1 | Immune and clinical findings of virus positive versus virus negative tumors among different cancer types.

\begin{tabular}{|c|c|c|c|c|c|c|c|}
\hline Virus $^{a}$ & Cancer $^{b}$ & $\begin{array}{l}\text { Positive } \\
\text { samples }\end{array}$ & Material $^{\mathrm{c}}$ & Method $^{d}$ & Immune cell infiltrate* & Clinical outcome* & Reference \\
\hline \multirow[t]{5}{*}{ MCPyV } & MCC & $\begin{array}{l}34 / 49 \\
(69.38 \%)\end{array}$ & FFPE & $\mathrm{IHC}$ & $\begin{array}{l}\uparrow \mathrm{CD} 4+\text { and } \mathrm{CD} 8+\mathrm{T} \text { cells } \\
\uparrow \mathrm{PD}-\mathrm{L} 1 \text { expression }\end{array}$ & $\uparrow \mathrm{OS}$ & $(120)$ \\
\hline & MCC & $\begin{array}{l}85 / 116 \\
(73.3 \%)\end{array}$ & FFPE & $\mathrm{IHC}$ & $\uparrow \mathrm{CD} 3+, \mathrm{CD} 8+, \mathrm{CD} 16+$, FoxP3+, and CD68+ cells & $\uparrow$ OS & $(121)$ \\
\hline & MCC & $\begin{array}{l}85 / 132 \\
(64 \%)\end{array}$ & FFPE & $\mathrm{IHC}$ & $\begin{array}{l}\uparrow \text { CD8+ cells } \\
\uparrow \text { PD-L1 Expression }\end{array}$ & $\uparrow$ OS and PFS & $(122)$ \\
\hline & MCC & $\begin{array}{l}84 / 134 \\
(62.68 \%)\end{array}$ & FFPE & $\mathrm{IHC}$ & $\uparrow$ CD8+ and FOXP3+ cells & - & (123) \\
\hline & MCC & $\begin{array}{l}38 / 49 \\
(79.2 \%)\end{array}$ & FFPE & $\mathrm{IHC}$ & No association & $\begin{array}{l}\uparrow \text { OS (high CD8+ T } \\
\text { cell infiltrate) } \\
\downarrow \text { OS (high viral load) }\end{array}$ & $(124)$ \\
\hline \multirow[t]{7}{*}{ HPV } & HNSCC & $13 / 27(48 \%)$ & FFPE & $\mathrm{IHC}$ & $\uparrow \mathrm{CD} 3+, \mathrm{CD} 4+, \mathrm{CD} 8+, \mathrm{CD} 20+$, and PD-1+ cells & - & $(125)$ \\
\hline & HNSCC & $\begin{array}{l}30 / 502 \\
(5.97 \%)\end{array}$ & RNA & RNA-seq & $\begin{array}{l}\uparrow \text { activated NK cells, Monocytes cells, Macrophages MO cells, } \\
\text { resting Dendritic cells, Neutrophil cells } \\
\uparrow \text { CXCL9 expression }\end{array}$ & - & (126) \\
\hline & HNSCC & $\begin{array}{l}9 / 63 \\
(14.28 \%)\end{array}$ & PBMC & $\begin{array}{l}\text { FACS } \\
\text { scRNA-seq }\end{array}$ & $\uparrow \mathrm{CD} 4+\mathrm{TFH}$, Germinal center (GC) B cells & $\uparrow \mathrm{PFS}$ (GC B cells) & $(127)$ \\
\hline & HNSCC & $\begin{array}{l}11 / 38 \\
(28.9 \%)\end{array}$ & PBMC & $\begin{array}{l}\text { FACS } \\
\Vdash H C\end{array}$ & $\begin{array}{l}\uparrow \text { CD45+ lymphocytes and B cells (CD19+/CD20+) } \\
\downarrow \text { CD86+/CD21 - antigen-presenting B cells }\end{array}$ & - & $(128)$ \\
\hline & OPSCC & $\begin{array}{l}63 / 72 \\
(87.5 \%)\end{array}$ & $\begin{array}{l}\text { FFPE } \\
\text { Fresh } \\
\text { tissue }\end{array}$ & $\begin{array}{l}\text { FACS } \\
\mathrm{IHC}\end{array}$ & $\begin{array}{l}\uparrow \mathrm{CD} 20+\mathrm{B} \text { cells } \\
\uparrow \mathrm{CD} 8+\top \text { cells }\end{array}$ & - & $(129)$ \\
\hline & ScC & $8 / 31(26 \%)$ & FFPE & $\mathrm{IHC}$ & $\uparrow \mathrm{CD} 8+$ & - & $(130)$ \\
\hline & HNSCC & $8 / 34(24 \%)$ & $\begin{array}{l}\text { PBMC } \\
\text { FFPE }\end{array}$ & $\begin{array}{l}\text { FACS } \\
\mathrm{IHC}\end{array}$ & $\begin{array}{l}\uparrow \text { CD45+ lymphocytes } \\
\uparrow \mathrm{PD}-1+\top\end{array}$ & - & $(131)$ \\
\hline \multirow[t]{7}{*}{ EBV } & GC & $32 / 571(5 \%)$ & FFPE & $\mathrm{IHC}$ & $\uparrow$ CD8+ and FOXP3+ T cells & $\uparrow$ OS & $(132)$ \\
\hline & GC & $12 / 71(17 \%)$ & $\begin{array}{l}\text { Fresh } \\
\text { tissue } \\
\text { FFPE }\end{array}$ & $\begin{array}{l}\text { RNA-seq } \\
\text { (TCGA) } \\
\text { qRT-PCR } \\
\text { IHC }\end{array}$ & $\begin{array}{l}\uparrow \text { CD8+ and NK cells } \\
\uparrow \text { ISGs }\end{array}$ & - & $(133)$ \\
\hline & GC & - & FFPE & $\mathrm{IHC}$ & $\uparrow$ Proliferating $(\mathrm{Ki} 67+)$ CD8+ T cells & - & $(134)$ \\
\hline & GC & $45 / 90(50 \%)$ & $\begin{array}{l}\text { Fresh } \\
\text { tissue } \\
\text { FFPE }\end{array}$ & $\begin{array}{l}\mathrm{IHC} \\
\text { FACS }\end{array}$ & $\begin{array}{l}\uparrow \text { Tregs } \\
\uparrow \text { CCL22 expression }\end{array}$ & - & $(135)$ \\
\hline & GC & $6 / 43(14 \%)$ & FFPE & $\mathrm{IHC}$ & $\uparrow$ CD8+ and CD4+ cells and macrophages & - & $(136)$ \\
\hline & GC & $\begin{array}{l}28 / 129 \\
(22 \%)\end{array}$ & FFPE & $\mathrm{IHC}$ & $\downarrow$ M2 macrophages (CD204+ cells) & $\uparrow$ OS & $(137)$ \\
\hline & GC & 20/48 (42\%) & FFPE & $\mathrm{HC}$ & $\begin{array}{l}\uparrow \mathrm{GzB} 7+\mathrm{CD} 8+\mathrm{T} \text { cells } \\
\uparrow \mathrm{MHC}-\|\end{array}$ & $\downarrow$ LN metastasis & (138) \\
\hline \multirow[t]{4}{*}{ HBV } & $\mathrm{HCC}$ & $\begin{array}{l}24 / 46 \\
(52.17 \%)\end{array}$ & $\begin{array}{l}\text { Fresh } \\
\text { tissue } \\
\text { PBMC }\end{array}$ & scRNA-seq & $\uparrow \operatorname{Trm}(\mathrm{PD}-1$-low/TOX-low) & $\uparrow \mathrm{RFS}$ & (139) \\
\hline & $\mathrm{HCC}$ & $\begin{array}{l}361 / 411 \\
(88 \%)\end{array}$ & FFPE & $\mathrm{IHC}$ & $\begin{array}{l}\uparrow \mathrm{CD} 8+ \\
\uparrow \mathrm{PD}-\mathrm{L} 1 \mathrm{TIL}\end{array}$ & - & $(140)$ \\
\hline & $\mathrm{HCC}$ & $\begin{array}{l}123 / 123 \\
(100 \%)\end{array}$ & PBMC & $\begin{array}{l}\text { FACS } \\
\mathrm{IHC}\end{array}$ & $\begin{array}{l}\uparrow \text { Treg (CD4+CD25+FoxP3+) TILs } \\
\downarrow \text { CD8+ TILs } \\
\downarrow \text { Perforin, granzyme A and B in CD8 }{ }^{+} T \text { cells }\end{array}$ & $\begin{array}{l}\downarrow \text { OS associated with } \\
\text { Tregs }\end{array}$ & $(141)$ \\
\hline & HCC & $12 / 20(60 \%)$ & $\begin{array}{l}\text { Fresh } \\
\text { tissue }\end{array}$ & $\mathrm{IHC}$ & $\uparrow P D-L 1$ & - & $(142)$ \\
\hline \multirow[t]{2}{*}{ HCMV } & GC & $\begin{array}{l}504 / 573 \\
(88 \%)\end{array}$ & FFPE & $\begin{array}{l}\text { IHC } \\
\text { TMA } \\
\text { RNA-seq }\end{array}$ & $\uparrow \mathrm{CD} 4+, \mathrm{CD} 8+, \mathrm{CD} 66 \mathrm{~b}+$, and CD163+ cells & $\begin{array}{l}\uparrow \mathrm{OS} \\
\uparrow \mathrm{RFS}\end{array}$ & $(143)$ \\
\hline & CRC & $\begin{array}{l}43 / 95 \\
(45.3 \%)\end{array}$ & $\begin{array}{l}\text { Fresh } \\
\text { tissue }\end{array}$ & PCR array & $\uparrow$ Th17 signature & $\downarrow$ DFS & $(144)$ \\
\hline
\end{tabular}

*Unless otherwise specified, comparisons refer to virus-positive versus virus-negative tumors.

${ }^{a}$ MCPyV, Merkel-cell polyomavirus; HPV, Human papillomavirus; EBV, Epstein-Barr virus; HBV, Hepatitis B virus; HCMV, Human cytomegalovirus.

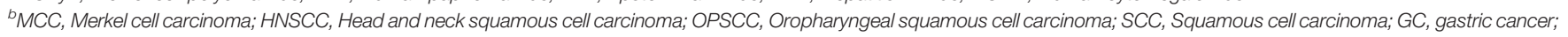
HCC, Hepatocellular carcinoma; CRC, Colorectal cancer.

${ }^{c}$ FFPE, Formalin-fixed paraffin-embedded tissue; RNA, Ribonucleic acid; PBMC, Peripheral blood mononuclear cells.

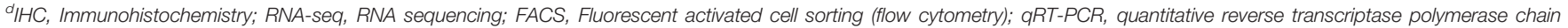
reaction; TMA, tissue microarray; PCR, Polymerase chain reaction. 
niches for antigen presentation in the TME and are associated with improved prognosis and response to ICB in multiple cancers (145).

Taking advantage of The Cancer Genome Atlas (TCGA) data (146), Rooney et al. have shown that EBV infection in stomach cancer and HPV infection in head and neck squamous cell carcinoma (HNSCC) were associated with high cytolytic scores, which were indicative of improved cytotoxic $\mathrm{T}$ cell activity (13). Subsequent analysis also suggested that, apart from HBV-infected liver hepatocellular carcinomas (LIHCs), virus-infected tumors had higher cytolytic cell infiltration when compared to non-infected tumors of the same type (147). Also, decreased TCR clonality was observed in EBVinfected stomach cancers, suggesting that antigen-driven clonal expansion of $\mathrm{T}$ lymphocytes was taking place in these tumors (147).

$\mathrm{T}$ cell co-stimulatory and inhibitory receptors and ligands, as well as memory and resident $\mathrm{T}$ cell markers, were increased in tumors positive for HPV, EBV and CMV, but not $\mathrm{HBV}^{+} \mathrm{LIHC}$ (148). Of note, gene expression signatures associated with viral infection were predictive of better overall survival in HNSCC and bladder cancer (147), and high $\mathrm{T}$ cell infiltration was predictive of overall survival in $\mathrm{HPV}^{+}$HNSCC but not in $\mathrm{HPV}^{-}$samples (148). In gastric cancer, $\mathrm{EBV}^{+}$tumors also had increased expression of immune checkpoints (149) and IRF3 gene signature (150). Using single-cell transcriptomics, it has recently been shown that malignant cells from $\mathrm{EBV}^{+}$gastric cancers were distinguished by a gene expression signature composed of IFN-I-activated and antigen-presenting molecules (151).

Oncovirus-specific $\mathrm{T}$ cells and epitopes have also been characterized in virus-associated tumors, such as MCPyVassociated Merkel cell carcinoma (152); HPV-associated cervical cancer $(153,154)$ and HNSCC (155-158); EBVassociated nasopharyngeal carcinoma $(159,160)$ and gastric cancer (161); and HBV-associated hepatocellular carcinomas $(139,162)$. Surgical removal of HPV-positive tumors followed by HPV vaccination has shown promising results to prevent cervical cancer recurrence $(163,164)$ and the use of virus-specific $\mathrm{T}$ cells or $\mathrm{T}$ cells engineered to recognize virus-derived antigens have shown promising results in preclinical models, case reports and clinical trials in multiple cancers (165-167), suggesting that recognition of viral antigens by cells of the adaptive immune system is a crucial feature controlling the growth and therapeutic response of virus-associated cancers.

However, the boosting of anti-tumor immune responses by viruses is not restricted to oncogenic viruses: recent reports highlight that commensal viruses are protective against tumors. In murine models of cutaneous squamous cell carcinoma (cSCC), infection by mouse papillomavirus 1 (MmuVP1) prior to carcinogen-induced skin cancer development delayed tumor formation and progression and prolonged survival in a $\mathrm{CD} 8^{+} \mathrm{T}$ cell-dependent fashion (168). Conversely, higher $\beta$-HPV RNA and DNA were found in cSCC of immunosuppressed patients relative to their immunocompetent counterparts, and $\mathrm{CD} 8^{+} \mathrm{T}$ cells isolated from human tumor tissues responded to peptides from the E7 protein of commensal $\beta-\mathrm{HPV}$, but not to the oncogenic HPV-16, suggesting that immunocompetent patients had active immune responses against $\beta$-HPV operating in the TME (168).

Of note, virus-specific bystander T cells are abundantly found in the tumor core of murine models of cancer (169) and human tumors $(170,171)$. These cells constitute a tissue-resident memory $\mathrm{T}$ cell population expanded by multiple viral infections throughout host lifetime that may be recruited to tumor tissues through CXCR3 interaction with intratumorallysecreted CXCL9 and CXCL10 (172) and can be (re)activated by IFN-I stimulation (173). Recent reports indicated that bystander $\mathrm{T}$ cells are less prone to terminal exhaustion than tumor-antigenspecific T cells (169), and their activation in the TME may boost antitumor immunity not only through secretion of proinflammatory factors, but also through antigen-independent killing of tumor cells in a NKG2D-dependent manner $(174,175)$.

Notably, repeated exposure to cognate viral-antigen makes $\mathrm{CD}^{+} \mathrm{T}$ cells more sensitive to antigen-independent bystander activation in cancer, suggesting that $\mathrm{CD} 8^{+} \mathrm{T}$ cells responsive to common human viruses, such as CMV, EBV and influenza, may be the best targets to boost antitumor immunity (176). Consistently, lung infection by influenza virus protected mice against lung colonization of B16F10 melanoma cells injected intravenously, and hospitalization for influenza infection during cancer treatment was protective against death in lung cancer patients (177). In this context, pre-clinical models have also shown that intratumoral administration of non-adjuvanted influenza vaccine delayed tumor growth and boosted the response to anti-PD-1 immunotherapy, mainly by recruiting and activating cross-presenting dendritic cells and $\mathrm{CD}^{+} \mathrm{T}$ cells (177). In another murine model, non-adjuvanted vaccination resulted in reactivation of bystander virus-specific tissue-resident memory T cells as well as dendritic and NK cells, which favored tumor growth arrest, synergizing with ICB (171). Importantly, at distant anatomical sites from tumors, viruses can promote tumor growth by shunting tumor-reactive immune cells to the infected tissue (178).

Collectively, these data show that virus-infected tumors have increased immunogenicity and that localized (but not distal) activation of virus-specific $\mathrm{T}$ cells might restrain tumor growth by directly killing tumor cells, as known for oncoviruses. In addition, activation of intratumor immune responses by bystander virus-specific tissue-resident $\mathrm{T}$ cells may boost antitumor immunity.

\section{ENDOGENOUS RETROVIRAL ELEMENTS AND TUMOR IMMUNITY}

Endogenous retroviral elements (EREs) are retrovirus-derived DNA sequences incorporated into the genome of host species through ancient infection of germinative cells. These elements comprise approximately $45 \%$ of the entire human genome and can be broadly classified into long terminal repeat (LTR) and non-LTR EREs (10). LTR-EREs can be further classified into 
(i) endogenous retroviruses (ERVs, or HERVs, in the case of human ERVs), in which LTRs flank complete or partial classical proviral sequences; (ii) mammalian-apparent LTR transposons (MaLRs); and (iii) solo LTRs. Non-LTR sequences otherwise comprise long and short interspaced elements (LINEs and SINEs, respectively) and Alu elements (10).

These elements are unable to generate provirus structures due to mutations in their ORFs actively generated through cellular viral restriction enzymes and therefore they cannot infect other cells. However, their ORFs can be transcribed into RNA and translated into proteins, and many of them hold the capacity to generate copies of themselves and reintegrate into the cellular genome, being called transposable elements (TEs) or transposons. Type-I TEs replicate into RNA sequences and use reverse transcriptase to copy themselves into DNA prior to reintegration, while type-II TEs simply encode enzymes called transposases to be excised and reintegrated into the genome as DNA (12).

Given the random nature of insertion events, EREs can modify the cellular genomic architecture and trigger many phenotypic alterations: their insertion into coding regions can inactivate genes, while intergenic re-insertions can modify the expression of proximal genes, since EREs can act as cryptic promoters. Also, the sequence similarity shared between EREs, especially between ERVs, in different chromosomal loci can promote non-homologous recombination, resulting in chromosomal aberrations such as translocations, deletions and inversions $(179,180)$.

In addition to the carcinogenic role on genomic instability, EREs may trigger immune responses when aberrantly expressed through the activation of innate immune receptors $(179,181)$, and their expression is associated with increased immune infiltrates and immune gene signatures in multiple cancers (13, 14, 182). Similarly, the enhanced immunogenicity of breast cancer models after treatment with CDK4/6 inhibitors (183) and the natural immunogenicity of rhabdoid tumors (184) were attributed to the expression of EREs and activation of IFN-I and III signaling pathways.

Due to the potential in generating genomic instability, EREs are tightly controlled by epigenetic mechanisms (185-187). Regarding ERVs, it has been shown that young sequences (i.e., those that have been incorporated into the genome more recently in the evolutionary history and predominantly contain more conserved ORFs) are repressed mainly by methylation of $\mathrm{CpG}$ islands in their LTRs and could have their expression reactivated by DNA hypomethylating agents (DHA) such as 5-aza-2'deoxycytidine, while older ERVs are less enriched in $\mathrm{CpG}$ islands and are mainly controlled by histone modifications, particularly histone $\mathrm{H} 3$ lysine 9 trimethylation (H3K9me3) (188). Interestingly, the natural resistance to carcinogenesis observed in blind mole rats has been recently attributed to their loose epigenetic control of EREs: since their tissues express low levels of DNA methyltransferase 1 (DNMT1), uncontrolled proliferation leads to loss in control of EREs expression leading to cGAS-STING triggering, IFN-I response activation and cell death (189).

Strikingly, treatment of tumor cells with DHA and histone deacetylase inhibitors (HDACi) led to the expression of EREs that could be detected through MDA-5 in the form of cytoplasmic dsRNA, formed by hybridization between complementary RNA strands expressed from bidirectional transcription of EREs (190), homologous EREs transcribed from different loci and from loop structures formed by transcription of DNA stretches containing homologous antisense-oriented EREs sequences (187). This ERE detection by cytoplasmic sensors induces an IFN-mediated antiviral state marked by enhanced cancer cell apoptosis and activation of innate and adaptive immunity that could favor responses to ICB with anti-CTLA-4 (191-193). Further research identified Alu elements as major source of dsRNA activating MDA-5, whereas ADAR1, an interferon-induced adenosine deaminase that takes part in innate immunity to viruses, has been thought to be a negative regulator of these elements, thus downmodulating MDA-5 and IFN responses (194). Notably, ADAR1 depletion in patient-derived colorectal cancer cells increased their in vitro and in vivo sensitivity to DNA hypomethylating agents (194).

ERVs have also been shown to significantly contribute to the pool of tumor antigens recognized by $\mathrm{CD} 8^{+} \mathrm{T}$ cells, therefore also contributing to the activation of adaptive anti-tumor immune responses. In renal cell carcinoma (RCC), HERV-E is selectively expressed in cancer cells lacking the VHL tumor suppressor (195), and peptides derived from its envelope protein have been shown to bind HLA-A ${ }^{\star} 0201$ and stimulate patient-derived CD8 ${ }^{+}$ $\mathrm{T}$ cells (196). Interestingly, following hematopoietic stem cell transplantation, tumor-directed immune responses consistent with graft versus tumor reactions targeted HERV-E epitopes and promoted regression of metastatic cancer in RCC patients (197). In clear cell RCC (ccRCC), immunogenic HERVs were associated with increased expression of immune signatures and response to anti-PD-1 and anti-PD-L1 (198). Notably, a recent report identified and validated 30 epitopes derived from HERV 4700 that could be recognized by $\mathrm{CD}^{+} \mathrm{T}$ cells from ccRCC patients and whose expression was also associated with improved response to anti-PD-1 therapy (182).

Indeed, using murine cell lines and tumor models, it has been shown that intergenic regions mapping transposable elements were the main source of epitopes targeted in anti-tumor immune responses boosted by immunotherapy, which could also be efficiently used in vaccination protocols, improving survival (199). Accordingly, transcripts overlapping LTR sequences in human cancers were thoroughly characterized in the TCGA database, wherein LTR-overlapping transcripts with prognostic implications have been identified, particularly in melanoma. Immunopeptidome of melanoma biopsies revealed some LTR-overlapping products capable of binding to MHC-I alleles (200). Of note, recognition of a HERV-derived epitope by $\mathrm{CD}^{+} \mathrm{T}$ cells in a melanoma patient had also been previously demonstrated (201).

In another report, EREs transcript expression in TCGA pancancer datasets was also associated with increased expression of immune-related genes, and treatment of glioblastoma cells with DHA promoted increased presentation of ERE-derived peptides via MHC-I (14). HERV-derived epitopes have also been characterized in both ovarian cancer (202) and hematological 
malignancies from the myeloid lineage (203). Multi-dimensional proteogenomic studies integrating data from exome sequencing, whole bulk and single-cell transcriptomics, sequencing of ribosome-bound RNA (Ribo-seq) and mass spectrometrybased immunopeptidome confirmed EREs as important epitope sources in cancers (204).

In summary, these data indicate that modulation of EREs expression in tumor cells by epigenetic modulators, such as DHA and HDACi, holds promising effects in anti-cancer therapies, especially ICB, since it can enhance tumor-cell death and immunogenicity by the activation of IFN-I and -III responses in the TME or unleashing tumor-associated antigens that could be targeted by cytotoxic $\mathrm{T}$ cells activated in this therapeutic modality (204-207).

\section{ANTIVIRAL IMMUNE RESPONSES AND CANCER: THERAPEUTIC OPPORTUNITIES}

Knowledge regarding the anti-tumor roles of antiviral immunity through the activation of IFN-I and IFN-III has opened new opportunities for cancer therapeutics. Currently, there exists an abundance of anti-cancer agents aimed at modulating these responses in TME under investigation in preclinical models and clinical trials, either as single agents or adjuvants for other immunotherapy (Table 2).

Also, the capacity of some viruses to directly induce cancer cell death and tumor regression, the so-called oncolytic viruses, has been largely reported and various families of viruses, including adenovirus, reovirus, Seneca Valley virus and herpesvirus, have been largely exploited therapeutically (208211). Currently, Zika virus (ZIKV), a neurotropic flavivirus that promotes death of embryonal neural cells and recently caused a microcephaly epidemic in South America (212), is being investigated for the treatment of embryonal central nervous system tumors, showing great oncolytic activity in preclinical models (213-215). Of note, at least part of this effect is mediated by activation of $\mathrm{CD} 8^{+} \mathrm{T}$ cells and this treatment may synergize with ICB (216). Nevertheless, no single unmodified virus has shown consistent clinical activity to merit approval.

The only oncolytic virus that has received approval from some regulatory agencies is talimogene laherparepvec (T-VEC) for the treatment of unresectable advanced cutaneous melanoma (217). TVEC is an engineered herpes simplex virus (HSV) type I designed to selectively replicate within and lyse tumor cells and concomitantly induce regional and systemic antitumor immunity. Two viral genes are deleted to attenuate neurovirulence, enhance tumor replication selectivity and improve antigen presentation of viral proteins in infected cells. T-VEC also carries the GM-CSF gene to improve the recruitment and activation of antigen-presenting cells and facilitate the adaptive $\mathrm{T}$ cell response. The intralesional administration of $\mathrm{T}$ VEC was compared with GM-CSF administered subcutaneously in a randomized phase III trial that recruited stage IIB and IV melanoma patients. T-VEC was associated with better durable response rates $(16.3 \% \times 2.1 \%, \mathrm{p}<0.001)$ and longer median OS (23.3 x 18.9 months, $\mathrm{p}=0.051)$ (217). Other modified viruses are under investigation for many different indications, as shown in Table 2.

As highlighted, interferon is produced by cells in response to viral infections and induces many modifications that restrain virus proliferation and contribute to their elimination. Similarly, interferon-dependent modifications are associated with tumor growth control and induction of effective antitumor immune response. Following this rationale, interferon has been used in the past to treat many different cancers, including renal cell carcinoma (218-220), melanoma (221-224), lymphoma (225), chronic myelogenous leukemia (226) and multiple myeloma (227), and although antitumor activity has been demonstrated, only a few patients benefit from such treatment. Indeed, some patients derived long-term disease control, albeit at the expense of significant systemic toxic effects, resulting in symptoms such as fever, chills, fatigue, depression and anorexia (52), therefore limiting its widespread use in clinical practice, mainly after the clinical implementation of ICB-based therapies.

Since most tumors present high genomic instability and defects in DNA repair genes, they usually exhibit a great amount of cytoplasmic DNA capable of triggering cGASSTING pathway activation and interferon production. STING agonists have been tested to treat cancer. DMXAA (ASA-404) or valdimesan was the first STING agonist tested. At that time, DMXAA was used at high doses as a vascular disrupting agent in mouse models, and regardless of promoting vascular necrosis and tumor regression, the TME remained poorly immunogenic, since high doses of DMXAA induced T cell apoptosis, a phenotype that favors rapid tumor regrowth (16). Despite this, a phase III trial compared carboplatin and paclitaxel with or without ASA-404 in metastatic NSCLC. The addition of ASA404 did not improve overall survival, progression-free survival, or overall response rate (228). It was subsequently shown that DMXAA does not bind properly to human STING (229). Although this class of drugs has shown great potential, there are no STING agonists approved yet. A great limitation of the STING agonists currently available is that they must be administered intratumorally; nevertheless, new drugs that can be given systemically are under investigation (Table 2) (16). Similarly, agonists of other innate immune sensors (TLR9 and TLR3 agonists) are also being tested in clinical trials (230) (Table 2).

HDACis and DHAs, such as DNA methyl-transferase inhibitors, are epigenetic modifiers that can promote alterations in both tumor cells and their microenvironment and ultimately enhance ICB efficacy. The synergistic effect of these drugs and ICB can be partly explained by the re-expression of EREs ("viral mimicry") in tumor cells and the induction of interferon responses (191, 206, 231) (Figure 4). Furthermore, these epigenetic modulators can exert direct effects on immune cells: HDACi and DHA treatment were shown to selectively deplete myeloid derived suppressor cells (MDSCs), leading to improved response to ICB in preclinical models (232); also, DHA treatment directly enhanced $\mathrm{CD}^{+} \mathrm{T}$ cell effector function and promoted better tumor control by modulating differential 
TABLE 2 | Recruiting studies testing immunotherapy in combination with drugs that induce antiviral-like responses.

\begin{tabular}{|c|c|c|c|c|c|}
\hline Drug/Product & Trial & Phase & Indication $^{a}$ & Combination & Identifier \\
\hline \multicolumn{6}{|l|}{ Oncolytic viruses } \\
\hline \multirow[t]{2}{*}{ ADV/HSV-tk } & STOMP & $\|$ & TNBC & $\begin{array}{l}\text { Pembrolizumab (anti- } \\
\text { PD1) }\end{array}$ & NCT03004183 \\
\hline & & & NSCLC & SBRT & \\
\hline Pelareorep & IRENE & $\|$ & TNBC & Retifanlimab (anti-PD1) & NCT04445844 \\
\hline $\begin{array}{l}\text { Pexastimogene Devacirepvec } \\
\text { (Pexa-Vec) }\end{array}$ & ISI-JX & I & Solid tumors & Ipilimumab (anti-CTLA4) & NCT02977156 \\
\hline Ad/MG1-E6E7 & Kingfisher & I & HPV related tumors & Atezolizumab (anti-PD-L1) & NCT03618953 \\
\hline TBio-6517 & RAPTOR & $\|$ & Solid tumors TNBC MS-colorectal cancer & Pembrolizumab & NCT04301011 \\
\hline Pelareorep & BRACELET-1 & $\|$ & Metastatic HR+/HER2- breast cancer & $\begin{array}{l}\text { Avelumab (anti-PD-L1) } \\
\text { Paclitaxel }\end{array}$ & NCT04215146 \\
\hline $\mathrm{RP}-1$ & CERPASS & $\|$ & Squamous skin cancer & Cemiplimab (anti-PD1) & NCT04050436 \\
\hline OBP-301 (Telomelysin) & & $\|$ & HNSCC & Pembrolizumab & NCT04685499 \\
\hline $\begin{array}{l}\text { Pexastimogene Devacirepvec } \\
\text { (Pexa-Vec) }\end{array}$ & & $\|$ & Renal cell carcinoma & Cemiplimab & NCT03294083 \\
\hline \multicolumn{6}{|l|}{ Interferon } \\
\hline $\begin{array}{l}\text { Recombinant interferon alpha } \\
\text { 2b-like protein }\end{array}$ & & $\|$ & Fibrolamellar hepatocelularcarcinoma & $\begin{array}{l}\text { Nivolumab (anti-PD1) 5- } \\
\text { fluorouracyl }\end{array}$ & NCT04380545 \\
\hline \multicolumn{6}{|l|}{ STING agonists } \\
\hline TAK-676 & & । & Solid tumors & Pembrolizumab & NCT04420884 \\
\hline E7766 & INSTAL-101 & I & $\begin{array}{l}\text { Lymphoma } \\
\text { Solid tumors }\end{array}$ & & NCT04144140 \\
\hline SNX281 & & I & $\begin{array}{l}\text { Lymphoma } \\
\text { Solid tumors }\end{array}$ & Pembrolizumab & NCT04609579 \\
\hline \multicolumn{6}{|l|}{ Epigenetic modifiers } \\
\hline Vorinostat & PEVOsq & $\|$ & $\begin{array}{l}\text { Squamous cell carcinoma (lung, HN, vulva, } \\
\text { penis, anus, cervix) }\end{array}$ & Pembrolizumab & NCT04357873 \\
\hline Entinostat & $\begin{array}{l}\text { MORPHEUS } \\
\text { HR+BC }\end{array}$ & $\begin{array}{l}\text { (I randomized } \\
\text { (multiple arms) }^{\star}\end{array}$ & Breast cancer HR+/HER2- & Atezolizumab & NCT03280563 \\
\hline Epacadostat & POD1UM-204 & $|/| \mid$ & Endometrial cancer & Retifanlimab & NCT04463771 \\
\hline Epacadostat & & $\|$ & HNSCC & $\begin{array}{l}\text { Pembrolizumab } \\
\text { Electroporation }\end{array}$ & NCT03823131 \\
\hline Tinostamustine & ENIgMA & I & Pancreatic cancer & Nivolumab & NCT03903458 \\
\hline Decitabine & & $\|$ & Breast cancer HER2- & Pembrolizumab & NCT02957968 \\
\hline Tazemetostat & & $\mid / I I$ & Urothelial carcinoma & Pembrolizumab & NCT03854474 \\
\hline \multicolumn{6}{|l|}{ TLR9 agonists } \\
\hline SD-101 & & 1 & Non-Hodgkin's lymphoma & BMS986178 (anti-OX40) & NCT03410901 \\
\hline CMP-001 & & II (randomized) & Melanoma & Nivolumab & NCT04401995 \\
\hline \multicolumn{6}{|l|}{ TLR3 agonist } \\
\hline Poly-ICLC & & $|/| \mid$ & Colorectal cancer & Pembrolizumab & NCT02834052 \\
\hline Poly-ICLC & & I & Prostate cancer (neoadjuvant) & & NCT03262103 \\
\hline
\end{tabular}

expression of NFAT isoforms, which favored the $\mathrm{T}$ cell differentiation into effector cells and inhibited their terminal differentiation into exhausted cells (233).

Despite these promising results in preclinical models, little is known about the long-term effects of these treatments in human cancers. There are several ongoing clinical trials investigating epigenetic modifier drugs such as EZH2 (enhancer of zeste homologue 2), LSD1 (lysine-specific histone demethylase 1A), C9a (histone-lysine N-methyltransferase EHMT2) and BET (bromodomain and extra-terminal) inhibitors in combination with ICB or other immunotherapies $(207,234)$ (Table 2). Results from these trials are eagerly awaited to clarify the effects of these drugs beyond preclinical models and might establish them as a new class of anticancer drugs to be used in clinics.

\section{CONCLUDING REMARKS AND FUTURE PERSPECTIVES}

IFN-I and IFN-III signaling exert potent antitumor effects through the induction of an antiviral state within tumor cells, characterized by tumor cytostasis and apoptosis. These responses are crucial in mediating benefits to well-established therapeutic approaches, such as radiotherapy, chemotherapy and ICB-based immunotherapies. As such, the activation of these pathways in the TME may be used as a biomarker of therapeutic response and prognosis.

Also, strategies aiming to enhance antiviral responses in the TME have been exploited in preclinical models and clinical trials either as adjuvants or single agents to potentiate anti-tumor 


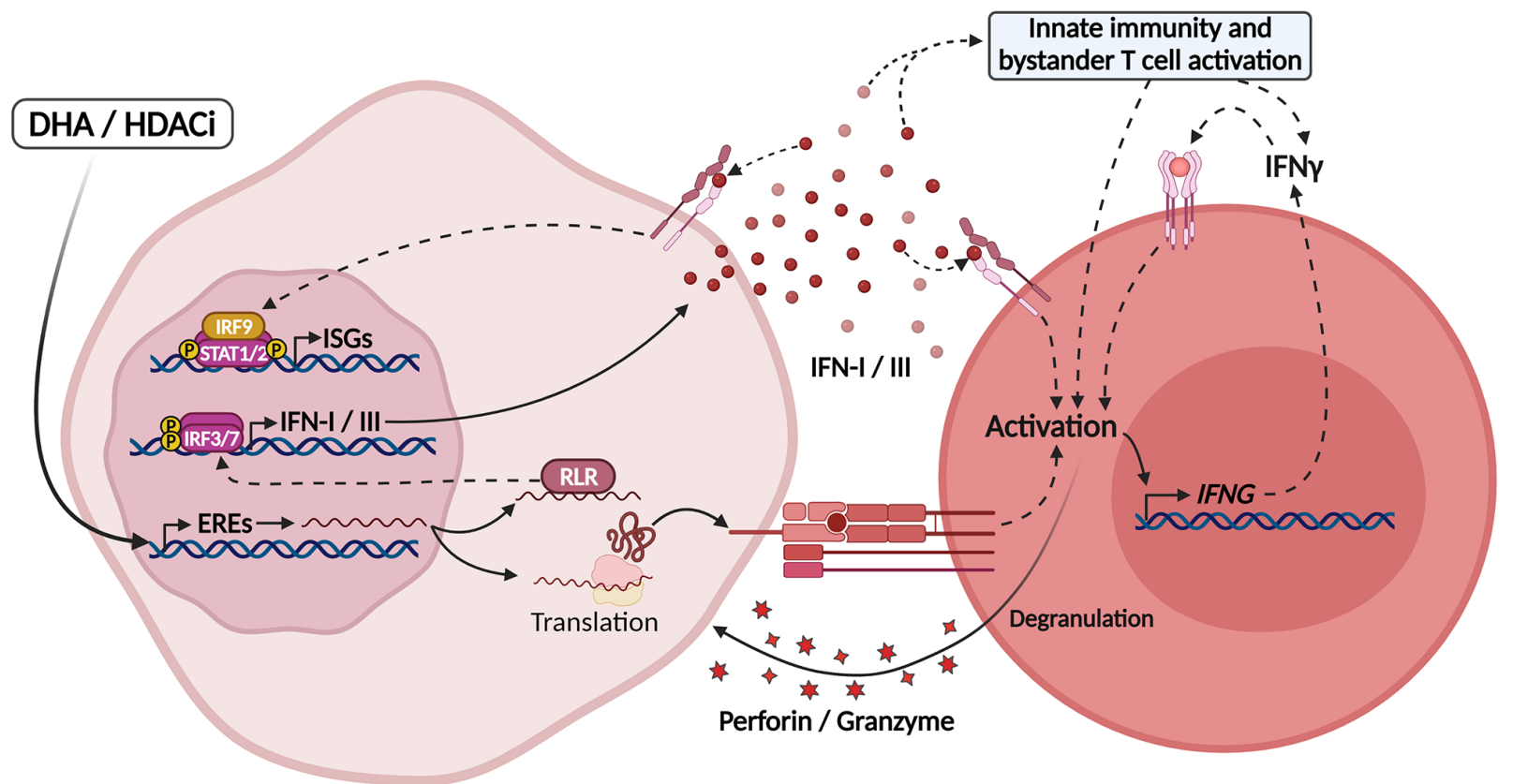

Cancer cell

$\mathrm{CD}^{+} \mathrm{T}$ cell

FIGURE 4 | Epigenetic modulators unleash EREs expression culminating in IFN-1/II secretion through activation of MDA5. Treatment with DNA hypomethylating agents (DHA) and histone deacetylase inhibitors (HDACi) lead to chromatin modifications and unleashing of endogenous retroviral elements (EREs) in tumor cells. The intermediates formed by these elements during their replication sensitize RIG-like receptors in the cytosol, such as MDA-5 and RIG-I, which activate IRF7/9 and the production of IFN-1/III. ERE-derived RNAs might also be translated in tumor cells generating tumor-associated antigens that may be recognized by CD8+ T cells. In this manner, DHA and HDACi increase tumor immunogenicity and might be explored as adjuvants for ICB therapies. Created with BioRender.com.

immune responses, with the aim of converting poorly immunogenic and refractory tumors into highly immune infiltrated tumors and boosting multiple therapeutic approaches. These strategies include (i) promotion of immunogenic cell death (e.g.: through oncolytic viruses and cytotoxic therapies, such as low dose radiotherapy and chemotherapy); (ii) direct activation of innate immunity sensors (e.g.: STING agonists) and (iii) reexpression of EREs through epigenetic modulation (e.g.: HDACi and DHA).

Therefore, IFN-I and III responses hold promising translational potential either as biomarkers or therapeutic targets in oncology, and this field might be revolutionized in the next few years by the approval of therapies capable of modulating antiviral responses that can cross-react with tumor cells, pointing out to their great potential to enhancing antitumor immune responses and overcome resistance to different therapeutic approaches.

\section{REFERENCES}

1. Zhang Y, Zhang Z. The History and Advances in Cancer Immunotherapy: Understanding the Characteristics of Tumor-Infiltrating Immune Cells and Their Therapeutic Implications. Cell Mol Immunol (2020) 17:807-21. doi: 10.1038/s41423-020-0488-6

\section{AUTHOR CONTRIBUTIONS}

GV: Conceptualization, writing, review, editing and figure design. WF: Conceptualization, writing, review and editing. VC: Writing, review and editing. TM: Conceptualization, supervision, writing, review and editing. All authors contributed to the article and approved the submitted version.

\section{FUNDING}

This work was supported by funds from the São Paulo Research Foundation (FAPESP) to GV (fellowship 2020/10299-7) and TM (grant 2018/14034-8), by grants from the National Institute of Science and Technology in Oncogenomics and Therapeutic Innovation (INCITO) funded by FAPESP (grant 2014/509431 ), and the National Council for Scientific and Technological Development (CNPq, grant 465682/2014-6).

2. Havel JJ, Chowell D, Chan TA. The Evolving Landscape of Biomarkers for Checkpoint Inhibitor Immunotherapy. Nat Rev Cancer (2019) 19:133-50. doi: 10.1038/s41568-019-0116-x

3. Bai R, Lv Z, Xu D, Cui J. Predictive Biomarkers for Cancer Immunotherapy With Immune Checkpoint Inhibitors. Biomark Res (2020) 8:34. doi: 10.1186/s40364-020-00209-0 
4. Binnewies M, Roberts EW, Kersten K, Chan V, Fearon DF, Merad M, et al. Microenvironment (TIME) for Effective Therapy. Nat Med (2018) 24:54150. doi: 10.1038/s41591-018-0014-x

5. Maleki Vareki S. High and Low Mutational Burden Tumors Versus Immunologically Hot and Cold Tumors and Response to Immune Checkpoint Inhibitors. J Immunother Cancer (2018) 6:157. doi: 10.1186/ s40425-018-0479-7

6. Bonaventura P, Shekarian T, Alcazer V, Valladeau-Guilemond J, ValsesiaWittmann S, Amigorena S, et al. Cold Tumors: A Therapeutic Challenge for Immunotherapy. Front Immunol (2019) 10:168. doi: 10.3389/fimmu.2019.00168

7. Mui U, Haley C, Tyring S. Viral Oncology: Molecular Biology and Pathogenesis. J Clin Med (2017) 6:111. doi: 10.3390/jcm6120111

8. Amarante MK, de Sousa Pereira N, Vitiello GAF, Watanabe MAE. Involvement of a Mouse Mammary Tumor Virus (MMTV) Homologue in Human Breast Cancer: Evidence for, Against and Possible Causes of Controversies. Microb Pathog (2019) 130:283-94. doi: 10.1016/j.micpath.2019.03.021

9. Michaelis M, Doerr HW, Cinatl J. The Story of Human Cytomegalovirus and Cancer: Increasing Evidence and Open Questions. Neoplasia (2009) 11:1-9. doi: 10.1593/neo.81178

10. Bourque G, Burns KH, Gehring M, Gorbunova V, Seluanov A, Hammell M, et al. Ten Things You Should Know About Transposable Elements. Genome Biol (2018) 19:199. doi: 10.1186/s13059-018-1577-z

11. Bannert N, Kurth R. Retroelements and the Human Genome: New Perspectives on an Old Relation. Proc Natl Acad Sci (2004) 101:14572-9. doi: $10.1073 /$ pnas. 0404838101

12. Kassiotis G. Endogenous Retroviruses and the Development of Cancer. J Immunol (2014) 192:1343-9. doi: 10.4049/jimmunol.1302972

13. Rooney MS, Shukla SA, Wu CJ, Getz G, Hacohen N. Molecular and Genetic Properties of Tumors Associated With Local Immune Cytolytic Activity. Cell (2015) 160:48-61. doi: 10.1016/j.cell.2014.12.033

14. Kong Y, Rose CM, Cass AA, Williams AG, Darwish M, Lianoglou S, et al. Transposable Element Expression is Associated With Immune in Fi Ltration. Nat Commun (2019) 10(1):5228. doi: 10.1038/s41467-019-13035-2

15. Smith C, Khanna R. Immune-Based Therapeutic Approaches to VirusAssociated Cancers. Curr Opin Virol (2018) 32:24-9. doi: 10.1016/ j.coviro.2018.08.010

16. Amouzegar A, Chelvanambi M, Filderman JN, Storkus WJ, Luke JJ. STING Agonists as Cancer Therapeutics. Cancers (Basel) (2021) 13:2695. doi: $10.3390 /$ cancers 13112695

17. Classon M, LaMarco K, De Carvalho DD. Drug-Induced Activation of "Junk" DNA - A Path to Combat Cancer Therapy Resistance? Oncoscience (2017) 4:115-6. doi: 10.18632/oncoscience.364

18. Thompson MR, Kaminski JJ, Kurt-jones EA, Fitzgerald KA. Pattern Recognition Receptors and the Innate Immune Response to Viral Infection. Viruses (2011) 3(6):920-40. doi: 10.3390/v3060920

19. Koyama S, Ishii KJ, Coban C, Akira S. Innate Immune Response to Viral Infection. Cytokine (2008) 43:336-41. doi: 10.1016/j.cyto.2008.07.009

20. Takeuchi O, Akira S. Pattern Recognition Receptors and Inflammation. Cell (2010) 140:805-20. doi: 10.1016/j.cell.2010.01.022

21. Ori D, Murase M, Kawai T. Cytosolic Nucleic Acid Sensors and Innate Immune Regulation. Int Rev Immunol (2017) 36:74-88. doi: 10.1080/ 08830185.2017.1298749

22. Walter MR. The Role of Structure in the Biology of Interferon Signaling. Front Immunol (2020) 11:606489. doi: 10.3389/fimmu.2020.606489

23. Kotenko SV, Gallagher G, Baurin VV, Lewis-Antes A, Shen M, Shah NK, et al. IFN- $\lambda$ s Mediate Antiviral Protection Through a Distinct Class II Cytokine Receptor Complex. Nat Immunol (2003) 4:69-77. doi: 10.1038/ni875

24. Chiang H-S, Liu HM. The Molecular Basis of Viral Inhibition of IRF- and STAT-Dependent Immune Responses. Front Immunol (2019) 9:3086. doi: 10.3389/fimmu.2018.03086

25. Schoggins JW. Interferon-Stimulated Genes: What Do They All do? Annu Rev Virol (2019) 6:567-84. doi: 10.1146/annurev-virology-092818-015756

26. Lee MS, Kim Y-J. Signaling Pathways Downstream of Pattern-Recognition Receptors and Their Cross Talk. Annu Rev Biochem (2007) 76:447-80. doi: 10.1146/annurev.biochem.76.060605.122847

27. Satoh T, Kato H, Kumagai Y, Yoneyama M, Sato S, Matsushita K, et al. LGP2 is a Positive Regulator of RIG-I- and MDA5-Mediated Antiviral Responses. Proc Natl Acad Sci (2010) 107:1512-7. doi: 10.1073/pnas.0912986107
28. Wu J, Sun L, Chen X, Du F, Shi H, Chen C, et al. Cyclic GMP-AMP Is an Endogenous Second Messenger in Innate Immune Signaling by Cytosolic DNA. Science (2013) 339:826-30. doi: 10.1126/science.1229963

29. Ma Z, Ni G, Damania B. Innate Sensing of DNA Virus Genomes. Annu Rev Virol (2018) 5:341-62. doi: 10.1146/annurev-virology-092917-043244

30. Lazear HM, Schoggins JW, Diamond MS. Shared and Distinct Functions of Type I and Type III Interferons. Immunity (2019) 50:907-23. doi: 10.1016/ j.immuni.2019.03.025

31. Wack A, Terczyńska-Dyla E, Hartmann R. Guarding the Frontiers: The Biology of Type III Interferons. Nat Immunol (2015) 16:802-9. doi: 10.1038/ ni. 3212

32. Mendoza JL, Schneider WM, Hoffmann HH, Vercauteren K, Jude KM, Xiong $\mathrm{A}$, et al. The IFN- $\lambda$-IFN- $\lambda$ r1-IL-10r $\beta$ Complex Reveals Structural Features Underlying Type III IFN Functional Plasticity. Immunity (2017) 46:379-92. doi: 10.1016/j.immuni.2017.02.017

33. Pervolaraki K, Stanifer ML, Münchau S, Renn LA, Albrecht D, Kurzhals S, et al. Type I and Type III Interferons Display Different Dependency on Mitogen-Activated Protein Kinases to Mount an Antiviral State in the Human Gut. Front Immunol (2017) 8:459. doi: 10.3389/fimmu.2017.00459

34. Hervas-Stubbs S, Perez-Gracia JL, Rouzaut A, Sanmamed MF, Le Bon A, Melero I. Direct Effects of Type I Interferons on Cells of the Immune System. Clin Cancer Res (2011) 17:2619-27. doi: 10.1158/1078-0432.CCR-10-1114

35. Castro F, Cardoso AP, Gonçalves RM, Serre K, Oliveira MJ. InterferonGamma at the Crossroads of Tumor Immune Surveillance or Evasion. Front Immunol (2018) 9:847. doi: 10.3389/fimmu.2018.00847

36. Crouse J, Kalinke U, Oxenius A. Regulation of Antiviral T Cell Responses by Type I Interferons. Nat Rev Immunol (2015) 15:231-42. doi: 10.1038/nri3806

37. van Boxel-Dezaire AHH, Rani MRS, Stark GR. Complex Modulation of Cell Type-Specific Signaling in Response to Type I Interferons. Immunity (2006) 25:361-72. doi: 10.1016/j.immuni.2006.08.014

38. Lee AJ, Ashkar AA. The Dual Nature of Type I and Type II Interferons. Front Immunol (2018) 9:2061. doi: 10.3389/fimmu.2018.02061

39. Aman MJ, Tretter T, Eisenbeis I, Bug G, Decker T, Aulitzky WE, et al. InterferonAlpha Stimulates Production of Interleukin-10 in Activated CD4+ T Cells and Monocytes. Blood (1996) 87:4731-6. doi: 10.1182/blood.V87.11.4731. bloodjournal87114731

40. Ziegler-Heitbrock L, Lötzerich M, Schaefer A, Werner T, Frankenberger M, Benkhart E. IFN- $\alpha$ Induces the Human IL-10 Gene by Recruiting Both IFN Regulatory Factor 1 and Stat3. J Immunol (2003) 171:285-90. doi: 10.4049/ jimmunol.171.1.285

41. Terawaki S, Chikuma S, Shibayama S, Hayashi T, Yoshida T, Okazaki T, et al. IFN- $\alpha$ Directly Promotes Programmed Cell Death-1 Transcription and Limits the Duration of T Cell-Mediated Immunity. J Immunol (2011) 186:2772-9. doi: 10.4049/jimmunol.1003208

42. Bazhin AV, von Ahn K, Fritz J, Werner J, Karakhanova S. Interferon- $\alpha$ UpRegulates the Expression of PD-L1 Molecules on Immune Cells Through STAT3 and P38 Signaling. Front Immunol (2018) 9:2129. doi: 10.3389/ fimmu.2018.02129

43. Benci JL, Xu B, Qiu Y, Wu TJ, Dada H, Twyman-Saint Victor C, et al. Tumor Interferon Signaling Regulates a Multigenic Resistance Program to Immune Checkpoint Blockade. Cell (2016) 167:1540-1554.e12. doi: 10.1016/ j.cell.2016.11.022

44. Jacquelot N, Yamazaki T, Roberti MP, Duong CPM, Andrews MC, Verlingue L, et al. Sustained Type I Interferon Signaling as a Mechanism of Resistance to PD1 Blockade. Cell Res (2019) 29:846-61. doi: 10.1038/s41422-019-0224-x

45. Zanoni I, Granucci F, Broggi A. Interferon (IFN)- $\lambda$ Takes the Helm: Immunomodulatory Roles of Type III IFNs. Front Immunol (2017) 8:1661. doi: 10.3389/fimmu.2017.01661

46. Koltsida O, Hausding M, Stavropoulos A, Koch S, Tzelepis G, Übel C, et al. IL-28a (IFN- $\lambda 2$ ) Modulates Lung DC Function to Promote Th1 Immune Skewing and Suppress Allergic Airway Disease. EMBO Mol Med (2011) 3:348-61. doi: 10.1002/emmm.201100142

47. Souza-Fonseca-Guimaraes F, Young A, Mittal D, Martinet L, Bruedigam C, Takeda K, et al. NK Cells Require IL-28R for Optimal In Vivo Activity. Proc Natl Acad Sci (2015) 112:E2376-84. doi: 10.1073/pnas.1424241112

48. Jordan WJ, Eskdale J, Srinivas S, Pekarek V, Kelner D, Rodia M, et al. Human Interferon Lambda-1 (IFN- $\lambda 1 /$ IL-29) Modulates the Th1/Th2 Response. Genes Immun (2007) 8:254-61. doi: 10.1038/sj.gene.6364382 
49. Dai J, Megjugorac NJ, Gallagher GE, Yu RYL, Gallagher G. IFN- $\lambda 1$ (IL-29) Inhibits GATA3 Expression and Suppresses Th2 Responses in Human Naive and Memory T Cells. Blood (2009) 113:5829-38. doi: 10.1182/blood-200809-179507

50. Morrow MP, Pankhong P, Laddy DJ, Schoenly KA, Yan J, Cisper N, et al. Comparative Ability of IL-12 and IL-28B to Regulate Treg Populations and Enhance Adaptive Cellular Immunity. Blood (2009) 113:5868-77. doi: 10.1182/blood-2008-11-190520

51. Misumi I, Whitmire JK. IFN- $\lambda$ Exerts Opposing Effects on T Cell Responses Depending on the Chronicity of the Virus Infection. J Immunol (2014) 192:3596-606. doi: 10.4049/jimmunol.1301705

52. Borden EC. Interferons $\alpha$ and $\beta$ in Cancer: Therapeutic Opportunities From New Insights. Nat Rev Drug Discov (2019) 18:219-34. doi: 10.1038/s41573018-0011-2

53. Gresser I, Bourali C, Lévy JP, Fontaine-Brouty-Boye D, Thomas MT. Increased Survival in Mice Inoculated With Tumor Cells and Treated With Interferon Preparations. Proc Natl Acad Sci USA (1969) 63:51-7. doi: $10.1073 /$ pnas.63.1.51

54. Gresser I, Belardelli F, Maury C, Maunoury MT, Tovey MG. Injection of Mice With Antibody to Interferon Enhances the Growth of Transplantable Murine Tumors. J Exp Med (1983) 158:2095-107. doi: 10.1084/jem.158.6.2095

55. Gresser I, Maury C, Vignaux F, Haller O, Belardelli F, Tovey MG. Antibody to Mouse Interferon Alpha/Beta Abrogates Resistance to the Multiplication of Friend Erythroleukemia Cells in the Livers of Allogeneic Mice. J Exp Med (1988) 168:1271-91. doi: 10.1084/jem.168.4.1271

56. Gutterman JU, Blumenschein GR, Alexanian R, Yap HY, Buzdar AU, Cabanillas F, et al. Leukocyte Interferon-Induced Tumor Regression in Human Metastatic Breast Cancer, Multiple Myeloma, and Malignant Lymphoma. Ann Intern Med (1980) 93:399-406. doi: 10.7326/0003-481993-3-399

57. How J, Hobbs G. Use of Interferon Alfa in the Treatment of Myeloproliferative Neoplasms: Perspectives and Review of the Literature. Cancers (Basel) (2020) 12:1954. doi: 10.3390/cancers12071954

58. Urabe A. Interferons for the Treatment of Hematological Malignancies. Oncology (1994) 51:137-41. doi: 10.1159/000227328

59. Ives NJ, Suciu S, Eggermont AMM, Kirkwood J, Lorigan P, Markovic SN, et al. Adjuvant Interferon- $\alpha$ for the Treatment of High-Risk Melanoma: An Individual Patient Data Meta-Analysis. Eur J Cancer (2017) 82:171-83. doi: 10.1016/j.ejca.2017.06.006

60. Fuertes MB, Kacha AK, Kline J, Woo SR, Kranz DM, Murphy KM, et al. Host Type I IFN Signals are Required for Antitumor CD8+ T Cell Responses Through CD8 $\alpha+$ Dendritic Cells. J Exp Med (2011) 208:2005-16. doi: 10.1084/jem.20101159

61. Ortiz A, Fuchs SY. Anti-Metastatic Functions of Type 1 Interferons: Foundation for the Adjuvant Therapy of Cancer. Cytokine (2017) 89:4-11. doi: 10.1016/j.cyto.2016.01.010

62. Dunn GP, Bruce AT, Sheehan KCF, Shankaran V, Uppaluri R, Bui JD, et al. A Critical Function for Type I Interferons in Cancer Immunoediting. Nat Immunol (2005) 6:722-9. doi: 10.1038/ni1213

63. Burnette BC, Liang H, Lee Y, Chlewicki L, Khodarev NN, Weichselbaum RR, et al. The Efficacy of Radiotherapy Relies Upon Induction of Type I Interferon-Dependent Innate and Adaptive Immunity. Cancer Res (2011) 71:2488-96. doi: 10.1158/0008-5472.CAN-10-2820

64. Hannesdóttir L, Tymoszuk P, Parajuli N, Wasmer MH, Philipp S, Daschil N, et al. Lapatinib and Doxorubicin Enhance the Stat1-Dependent Antitumor Immune Response. Eur J Immunol (2013) 43:2718-29. doi: 10.1002/ eji.201242505

65. Schiavoni G, Sistigu A, Valentini M, Mattei F, Sestili P, Spadaro F, et al. Cyclophosphamide Synergizes With Type I Interferons Through Systemic Dendritic Cell Reactivation and Induction of Immunogenic Tumor Apoptosis. Cancer Res (2011) 71:768-78. doi: 10.1158/0008-5472.CAN-10-2788

66. Sistigu A, Yamazaki T, Vacchelli E, Chaba K, Enot DP, Adam J, et al. Cancer Cell-Autonomous Contribution of Type I Interferon Signaling to the Efficacy of Chemotherapy. Nat Med (2014) 20:1301-9. doi: 10.1038/nm.3708

67. Werner LR, Kler JS, Gressett MM, Riegert M, Werner LK, Heinze CM, et al. Transcriptional-Mediated Effects of Radiation on the Expression of Immune Susceptibility Markers in Melanoma. Radiother Oncol (2017) 124:418-26. doi: 10.1016/j.radonc.2017.08.016
68. Angioli R, Sevin BU, Perras JP, Untch M, Koechli OR, Nguyen HN, et al. In Vitro Potentiation of Radiation Cytotoxicity by Recombinant Interferons in Cervical Cancer Cell Lines. Cancer (1993) 71:3717-25. doi: 10.1002/10970142(19930601)71:11<3717::aid-cncr2820711140>3.0.co;2-i

69. Deng L, Liang H, Xu M, Yang X, Burnette B, Arina A, et al. STINGDependent Cytosolic DNA Sensing Promotes Radiation-Induced Type I Interferon-Dependent Antitumor Immunity in Immunogenic Tumors. Immunity (2014) 41:843-52. doi: 10.1016/j.immuni.2014.10.019

70. Harding SM, Benci JL, Irianto J, Discher DE, Minn AJ, Greenberg RA. Mitotic Progression Following DNA Damage Enables Pattern Recognition Within Micronuclei. Nature (2017) 548:466-70. doi: 10.1038/ nature 23470

71. Rodriguez-Ruiz ME, Rodriguez I, Garasa S, Barbes B, Solorzano JL, PerezGracia JL, et al. Abscopal Effects of Radiotherapy Are Enhanced by Combined Immunostimulatory Mabs and Are Dependent on CD8 T Cells and Crosspriming. Cancer Res (2016) 76:5994-6005. doi: 10.1158/00085472.CAN-16-0549

72. Chen J, Cao Y, Markelc B, Kaeppler J, Vermeer JA, Muschel RJ. Type I IFN Protects Cancer Cells From CD8+ T Cell-Mediated Cytotoxicity After Radiation. J Clin Invest (2019) 129:4224-38. doi: 10.1172/JCI127458

73. Chen B, Alvarado DM, Iticovici M, Kau NS, Park H, Parikh PJ, et al. Interferon-Induced IDO1 Mediates Radiation Resistance and Is a Therapeutic Target in Colorectal Cancer. Cancer Immunol Res (2020) 8:451-64. doi: 10.1158/2326-6066.CIR-19-0282

74. Bernard JJ, Cowing-Zitron C, Nakatsuji T, Muehleisen B, Muto J, Borkowski AW, et al. Ultraviolet Radiation Damages Self Noncoding RNA and is Detected by TLR3. Nat Med (2012) 18:1286-90. doi: 10.1038/nm.2861

75. Tatematsu M, Nishikawa F, Seya T, Matsumoto M. Toll-Like Receptor 3 Recognizes Incomplete Stem Structures in Single-Stranded Viral RNA. Nat Commun (2013) 4:1833. doi: 10.1038/ncomms2857

76. Bidwell BN, Slaney CY, Withana NP, Forster S, Cao Y, Loi S, et al. Silencing of Irf7 Pathways in Breast Cancer Cells Promotes Bone Metastasis Through Immune Escape. Nat Med (2012) 18:1224-31. doi: 10.1038/nm.2830

77. Rautela J, Baschuk N, Slaney CY, Jayatilleke KM, Xiao K, Bidwell BN, et al. Loss of Host Type-I IFN Signaling Accelerates Metastasis and Impairs NKCell Antitumor Function in Multiple Models of Breast Cancer. Cancer Immunol Res (2015) 3:1207-17. doi: 10.1158/2326-6066.CIR-15-0065

78. Brockwell NK, Rautela J, Owen KL, Gearing LJ, Deb S, Harvey K, et al. Tumor Inherent Interferon Regulators as Biomarkers of Long- Term Chemotherapeutic Response in TNBC. NPJ Precis Oncol (2019) 3:21. doi: 10.1038/s41698-019-0093-2

79. Brockwell NK, Parker BS. Tumor Inherent Interferons: Impact on Immune Reactivity and Immunotherapy. Cytokine (2019) 118:42-7. doi: 10.1016/ j.cyto.2018.04.006

80. Demaria O, De Gassart A, Coso S, Gestermann N, Di Domizio J, Flatz L, et al. STING Activation of Tumor Endothelial Cells Initiates Spontaneous and Therapeutic Antitumor Immunity. Proc Natl Acad Sci USA (2015) 112:15408-13. doi: 10.1073/pnas.1512832112

81. Wang H, Hu S, Chen X, Shi H, Chen C, Sun L, et al. cGAS is Essential for the Antitumor Effect of Immune Checkpoint Blockade. Proc Natl Acad Sci (2017) 114:1637-42. doi: 10.1073/pnas.1621363114

82. Spiotto M, Fu Y-X, Weichselbaum RR. The Intersection of Radiotherapy and Immunotherapy: Mechanisms and Clinical Implications. Sci Immunol (2016) 1:eaag1266. doi: 10.1126/sciimmunol.aag1266

83. Vanpouille-Box C, Alard A, Aryankalayil MJ, Sarfraz Y, Diamond JM, Schneider RJ, et al. DNA Exonuclease Trex1 Regulates RadiotherapyInduced Tumour Immunogenicity. Nat Commun (2017) 8:15618. doi: $10.1038 /$ ncomms 15618

84. Herrera FG, Ronet C, Ochoa de Olza M, Barras D, Crespo I, Andreatta M, et al. Low Dose Radiotherapy Reverses Tumor Immune Desertification and Resistance to Immunotherapy. Cancer Discovery Candisc (2021), 0003.2021. doi: 10.1158/2159-8290.CD-21-0003

85. Tagawa M, Kawamura K, Li Q, Tada Y, Hiroshima K, Shimada H. A Possible Anticancer Agent, Type III Interferon, Activates Cell Death Pathways and Produces Antitumor Effects. Clin Dev Immunol (2011) 2011:1-6. doi: 10.1155/ 2011/479013

86. Abushahba W, Balan M, Castaneda I, Yuan Y, Reuhl K, Raveche E, et al. Antitumor Activity of Type I and Type III Interferons in BNL Hepatoma 
Model. Cancer Immunol Immunother (2010) 59:1059-71. doi: 10.1007/ s00262-010-0831-3

87. Lasfar A, Lewis-Antes A, Smirnov SV, Anantha S, Abushahba W, Tian B, et al. Characterization of the Mouse IFN- $\lambda$ Ligand-Receptor System: IFN- $\lambda s$ Exhibit Antitumor Activity Against B16 Melanoma. Cancer Res (2006) 66:4468-77. doi: 10.1158/0008-5472.CAN-05-3653

88. Li Q, Kawamura K, Ma G, Iwata F, Numasaki M, Suzuki N, et al. Interferon$\lambda$ Induces G1 Phase Arrest or Apoptosis in Oesophageal Carcinoma Cells and Produces Anti-Tumour Effects in Combination With Anti-Cancer Agents. Eur J Cancer (2010) 46:180-90. doi: 10.1016/j.ejca.2009.10.002

89. Li W, Lewis-Antes A, Huang J, Balan M, Kotenko SV. Regulation of Apoptosis by Type III Interferons. Cell Prolif (2008) 41:960-79. doi: 10.1111/j.1365-2184.2008.00558.x

90. Sato A, Ohtsuki M, Hata M, Kobayashi E, Murakami T. Antitumor Activity of IFN- $\lambda$ in Murine Tumor Models. J Immunol (2006) 176:7686-94. doi: 10.4049/jimmunol.176.12.7686

91. Hubert M, Gobbini E, Couillault C, Manh TV, Doffin AC, Berthet J, et al. IFN-III is Selectively Produced by Cdc1 and Predicts Good Clinical Outcome in Breast Cancer. Sci Immunol (2020) 5:eaav3942. doi: 10.1126/ sciimmunol.aav3942

92. Epstein MA, Barr YM. Cultivation In Vitro of Human Lymphoblasts From Burkitt's Malignant Lymphoma. Lancet (1964) 283:252-3. doi: 10.1016/ S0140-6736(64)92354-2

93. Epstein MA, Barr YM, Achong BG. A Second Virus-Carrying Tissue Culture Strain (EB2) of Lymphoblasts From Burkitt's Lymphoma. Pathol Biol (1964) 12:1233-4.

94. Cao J, Li D. Searching for Human Oncoviruses: Histories, Challenges, and Opportunities. J Cell Biochem (2018) 119:4897-906. doi: 10.1002/jcb.26717

95. Zapatka M, Borozan I, Brewer DS, Iskar M, Grundhoff A, Alawi M, et al. The Landscape of Viral Associations in Human Cancers. Nat Genet (2020) 52:320-30. doi: 10.1038/s41588-019-0558-9

96. Bouvard V, Baan R, Straif K, Grosse Y, Secretan B, El Ghissassi F, et al. A Review of Human Carcinogens-Part B: Biological Agents. Lancet Oncol (2009) 10:321-2. doi: 10.1016/S1470-2045(09)70096-8

97. de Martel C, Georges D, Bray F, Ferlay J, Clifford GM. Global Burden of Cancer Attributable to Infections in 2018: A Worldwide Incidence Analysis. Lancet Glob Heal (2020) 8:e180-90. doi: 10.1016/S2214-109X (19)30488-7

98. Marques MM, Berrington de Gonzalez A, Beland FA, Browne P, Demers PA, Lachenmeier DW, et al. Advisory Group Recommendations on Priorities for the IARC Monographs. Lancet Oncol (2019) 20:763-4. doi: 10.1016/S14702045(19)30246-3

99. Bhatia S, Afanasiev O, Nghiem P. Immunobiology of Merkel Cell Carcinoma: Implications for Immunotherapy of a PolyomavirusAssociated Cancer. Curr Oncol Rep (2011) 13:488-97. doi: 10.1007/ s11912-011-0197-5

100. de Almeida NAA, Ribeiro CR de A, Raposo JV, de Paula VS. Immunotherapy and Gene Therapy for Oncoviruses Infections: A Review. Viruses (2021) 13:822. doi: $10.3390 / \mathrm{v} 13050822$

101. Matsuoka M, Jeang K-T. Human T-Cell Leukemia Virus Type 1 (HTLV-1) and Leukemic Transformation: Viral Infectivity, Tax, HBZ and Therapy. Oncogene (2011) 30:1379-89. doi: 10.1038/onc.2010.537

102. Mesri EA, Cesarman E, Boshoff C. Kaposi's Sarcoma and its Associated Herpesvirus. Nat Rev Cancer (2010) 10:707-19. doi: 10.1038/nrc2888

103. Avilala J, Becnel D, Abdelghani R, Nanbo A, Kahn J, Li L, et al. Role of Virally Encoded Circular RNAs in the Pathogenicity of Human Oncogenic Viruses. Front Microbiol (2021) 12:657036. doi: 10.3389/fmicb.2021.657036

104. Krump NA, You J. Molecular Mechanisms of Viral Oncogenesis in Humans. Nat Rev Microbiol (2018) 16:684-98. doi: 10.1038/s41579-018-0064-6

105. Mesri EA, Feitelson MA, Munger K. Human Viral Oncogenesis: A Cancer Hallmarks Analysis. Cell Host Microbe (2014) 15:266-82. doi: 10.1016/ j.chom.2014.02.011

106. Soliman SHA, Orlacchio A, Verginelli F. Viral Manipulation of the Host Epigenome as a Driver of Virus-Induced Oncogenesis. Microorganisms (2021) 9:1179. doi: 10.3390/microorganisms 9061179

107. Song S, Gong S, Singh P, Lyu J, Bai Y. The Interaction Between Mitochondria and Oncoviruses. Biochim Biophys Acta Mol Basis Dis (2018) 1864:481-7. doi: 10.1016/j.bbadis.2017.09.023
108. Kori M, Arga KY. Pathways Involved in Viral Oncogenesis: New Perspectives From Virus-Host Protein Interactomics. Biochim Biophys Acta Mol Basis Dis (2020) 1866:165885. doi: 10.1016/j.bbadis.2020.165885

109. Tornesello ML, Annunziata C, Tornesello AL, Buonaguro L, Buonaguro FM. Human Oncoviruses and P53 Tumor Suppressor Pathway Deregulation at the Origin of Human Cancers. Cancers (Basel) (2018) 10:213. doi: 10.3390/ cancers 10070213

110. Ferreira DA, Tayyar Y, Idris A, McMillan NAJ. A "Hit-and-Run” Affair - A Possible Link for Cancer Progression in Virally Driven Cancers. Biochim Biophys Acta Rev Cancer (2021) 1875:188476. doi: 10.1016/j.bbcan. 2020.188476

111. Viarisio D, Müller-Decker K, Accardi R, Robitaille A, Durst M, Beer K, et al. Beta HPV38 Oncoproteins Act With a Hit-and-Run Mechanism in Ultraviolet Radiation-Induced Skin Carcinogenesis in Mice. PloS Pathog (2018) 14:e1006783. doi: 10.1371/journal.ppat.1006783

112. Roberts SA, Lawrence MS, Klimczak LJ, Grimm SA, Fargo D, Stojanov P, et al. An APOBEC Cytidine Deaminase Mutagenesis Pattern is Widespread in Human Cancers. Nat Genet (2013) 45:970-6. doi: 10.1038/ng.2702

113. Borzooee F, Asgharpour M, Quinlan E, Grant MD, Larijani M. Viral Subversion of APOBEC3s: Lessons for Anti-Tumor Immunity and Tumor Immunotherapy. Int Rev Immunol (2018) 37:151-64. doi: 10.1080/ 08830185.2017.1403596

114. Henderson S, Fenton T. APOBEC3 Genes: Retroviral Restriction Factors to Cancer Drivers. Trends Mol Med (2015) 21:274-84. doi: 10.1016/ j.molmed.2015.02.007

115. Henderson S, Chakravarthy A, Su X, Boshoff C, Fenton TR. APOBECMediated Cytosine Deamination Links PIK3CA Helical Domain Mutations to Human Papillomavirus-Driven Tumor Development. Cell Rep (2014) 7:1833-41. doi: 10.1016/j.celrep.2014.05.012

116. Riva G, Albano C, Gugliesi F, Pasquero S, Pacheco SFC, Pecorari G, et al. HPV Meets APOBEC: New Players in Head and Neck Cancer. Int J Mol Sci (2021) 22:1402. doi: 10.3390/ijms22031402

117. Revathidevi S, Murugan AK, Nakaoka H, Inoue I, Munirajan AK, et al. APOBEC: A Molecular Driver in Cervical Cancer Pathogenesis. Cancer Lett (2021) 496:104-16. doi: 10.1016/j.canlet.2020.10.004

118. Verhalen B, Starrett GJ, Harris RS. Functional Upregulation of the DNA Cytosine Deaminase APOBEC3B by Polyomaviruses. Cancer Lett (2016) 90:6379-86. doi: 10.1128/JVI.00771-16

119. Bobrovnitchaia I, Valieris R, Drummond RD, Lima JP, Freitas HC, Bartelli TF, et al. APOBEC-Mediated DNA Alterations: A Possible New Mechanism of Carcinogenesis in EBV-Positive Gastric Cancer. Int J Cancer (2020) 146:181-91. doi: 10.1002/ijc.32411

120. Lipson EJ, Vincent JG, Loyo M, Kagohara LT, Luber BS, Wang H, et al. PDL1 Expression in the Merkel Cell Carcinoma Microenvironment: Association With Inflammation, Merkel Cell Polyomavirus, and Overall Survival. Cancer Immunol Res (2013) 1:54-63. doi: 10.1158/2326-6066.CIR-13-0034

121. Sihto H, Böhling T, Kavola H, Koljonen V, Salmi M, Jalkanen S, et al. Tumor Infiltrating Immune Cells and Outcome of Merkel Cell Carcinoma: A Population-Based Study. Clin Cancer Res (2012) 18:2872-81. doi: 10.1158/ 1078-0432.CCR-11-3020

122. Donizy P, Wu CL, Kopczynski J, Pieniazek M, Biecek P, Rys J, et al. Prognostic Role of Tumoral PD-L1 and IDO1 Expression, and Intratumoral CD8+ and FoxP3+ Lymphocyte Infiltrates in 132 Primary Cutaneous Merkel Cell Carcinomas. Int J Mol Sci (2021) 22:5489. doi: 10.3390/ijms22115489

123. Donizy P, Wróblewska JP, Dias-Santagata D, Woznica K, Biecek P, Mochel MC, et al. Merkel Cell Carcinoma of Unknown Primary: Immunohistochemical and Molecular Analyses Reveal Distinct UV-Signature/MCPyV-Negative and High Immunogenicity/MCPyV-Positive Profiles. Cancers (Basel) (2021) 13:1621. doi: $10.3390 /$ cancers 13071621

124. von der Grün J, Winkelmann R, Meissner M, Wieland U, Silling S, Martin D, et al. Merkel Cell Polyoma Viral Load and Intratumoral CD8+ Lymphocyte Infiltration Predict Overall Survival in Patients With Merkel Cell Carcinoma. Front Oncol (2019) 9:20. doi: 10.3389/fonc.2019.00020

125. Succaria F, Kvistborg P, Stein JE, Engle EL, McMiller TL, Rooper LM, et al. Characterization of the Tumor Immune Microenvironment in Human Papillomavirus-Positive and -Negative Head and Neck Squamous Cell Carcinomas. Cancer Immunol Immunother (2021) 70:1227-37. doi: 10.1007/s00262-020-02747-w 
126. Zhou D, Wang J, Wang J, Liu X. Profiles of Immune Cell Infiltration and Immune-Related Genes in the Tumor Microenvironment of HNSCC With or Without HPV Infection. Am J Transl Res (2021) 13:2163-80.

127. Ruffin AT, Cillo AR, Tabib T, Liu A, Onkar S, Kunning SR, et al. B Cell Signatures and Tertiary Lymphoid Structures Contribute to Outcome in Head and Neck Squamous Cell Carcinoma. Nat Commun (2021) 12:3349. doi: 10.1038/s41467-021-23355-x

128. Lechner A, Schlößer HA, Thelen M, Wennhold K, Rothschild SI, Gilles R, et al. Tumor-Associated B Cells and Humoral Immune Response in Head and Neck Squamous Cell Carcinoma. Oncoimmunology (2019) 8:1535293. doi: 10.1080/2162402X.2018.1535293

129. Hladíková K, Koucký V, Bouček J, Laco J, Grega M, Hodek M, et al. TumorInfiltrating B Cells Affect the Progression of Oropharyngeal Squamous Cell Carcinoma via Cell-to-Cell Interactions With CD8+ T Cells. J Immunother Cancer (2019) 7:261. doi: 10.1186/s40425-019-0726-6

130. Nagarajan P, El-Hadad C, Gruschkus SK, Ning J, Hudgens CW, Sagiv O, et al. PD-L1/PD1 Expression, Composition of Tumor-Associated Immune Infiltrate, and HPV Status in Conjunctival Squamous Cell Carcinoma. Investig Opthalmol Vis Sci (2019) 60:2388. doi: 10.1167/iovs.19-26894

131. Lechner A, Schlosser H, Rothschild SI, Thelen M, Reuter S, Zentis P, et al. Characterization of Tumor-Associated T-Lymphocyte Subsets and Immune Checkpoint Molecules in Head and Neck Squamous Cell Carcinoma. Oncotarget (2017) 8:44418-33. doi: 10.18632/oncotarget.17901

132. Ma J, Li J, Hao Y, Nie Y, Li Z, Qian M, et al. Differentiated Tumor Immune Microenvironment of Epstein-Barr Virus-Associated and Negative Gastric Cancer: Implication in Prognosis and Immunotherapy. Oncotarget (2017) 8:67094-103. doi: 10.18632/oncotarget.17945

133. Strong MJ, Xu G, Coco J, Baribault C, Vinay DS, Lacey MR, et al. Differences in Gastric Carcinoma Microenvironment Stratify According to EBV Infection Intensity: Implications for Possible Immune Adjuvant Therapy. PloS Pathog (2013) 9:e1003341. doi: 10.1371/journal.ppat.1003341

134. Saiki Y, Ohtani H, Naito Y, Miyazawa M, Nagura H. Immunophenotypic Characterization of Epstein-Barr Virus-Associated Gastric Carcinoma: Massive Infiltration by Proliferating CD8+ T-Lymphocytes. Lab Invest (1996) $75: 67-76$

135. Zhang N, Chen J, Xiao L, Tang F, Zhang Z, Zhang Y, et al. Accumulation Mechanisms of CD4+CD25+FOXP3+ Regulatory T Cells in EBV-Associated Gastric Carcinoma. Sci Rep (2015) 5:18057. doi: 10.1038/srep18057

136. Kim TS, da Silva E, Coit DG, Tang LH. Intratumoral Immune Response to Gastric Cancer Varies by Molecular and Histologic Subtype. Am J Surg Pathol (2019) 43:851-60. doi: 10.1097/PAS.0000000000001253

137. Ichimura T, Abe H, Morikawa T, Yamashita H, Ishikawa S, Ushiku T, et al. Low Density of CD204-Positive M2-Type Tumor-Associated Macrophages in Epstein-Barr Virus-Associated Gastric Cancer: A Clinicopathologic Study With Digital Image Analysis. Hum Pathol (2016) 56:74-80. doi: 10.1016/ j.humpath.2016.06.002

138. van Beek J, zur Hausen A, Snel SN, Berkhof J, Kranenbarg EK, van de Velde CJ, et al. Morphological Evidence of an Activated Cytotoxic T-Cell Infiltrate in EBV-Positive Gastric Carcinoma Preventing Lymph Node Metastases. Am J Surg Pathol (2006) 30:59-65. doi: 10.1097/01.pas.0000176428.06629.1e

139. Cheng Y, Gunasegaran B, Singh HD, Dutertre CA, Loh CY, Lim JQ, et al. NonTerminally Exhausted Tumor-Resident Memory HBV-Specific T Cell Responses Correlate With Relapse-Free Survival in Hepatocellular Carcinoma. Immunity (2021) 54:1825-1840.e7. doi: 10.1016/j.immuni.2021.06.013

140. Huang C, Wang Y, Luo GY, Han F, Li YQ, Zhou ZG, et al. Relationship Between PD-L1 Expression and CD8+ T-Cell Immune Responses in Hepatocellular Carcinoma. J Immunother (2017) 40:323-33. doi: 10.1097/ CJI.0000000000000187

141. Fu J, Xu D, Liu Z, Shi M, Zhao P, Fu B, et al. Increased Regulatory T Cells Correlate With CD8 T-Cell Impairment and Poor Survival in Hepatocellular Carcinoma Patients. Gastroenterology (2007) 132:2328-39. doi: 10.1053/ j.gastro.2007.03.102

142. Wang BJ, Bao JJ, Wang JZ, Wang Y, Jiang M, Xing MY, et al. Immunostaining of PD-1/PD-Ls in Liver Tissues of Patients With Hepatitis and Hepatocellular Carcinoma. World J Gastroenterol (2011) 17:3322. doi: 10.3748/wjg.v17.i28.3322

143. Ye S, Hu Y, Chen $\mathrm{C}$, Chen S, Tong $\mathrm{X}$, Zhu H, et al. The Human Cytomegalovirus US31 Gene Predicts Favorable Survival and Regulates the
Tumor Microenvironment in Gastric Cancer. Front Oncol (2021) 11:614925. doi: $10.3389 /$ fonc.2021.614925

144. Chen HP, Jiang JK, Lai PY, Chen CY, Chou TY, Chen YC, et al. Tumoral Presence of Human Cytomegalovirus is Associated With Shorter DiseaseFree Survival in Elderly Patients With Colorectal Cancer and Higher Levels of Intratumoral Interleukin-17. Clin Microbiol Infect (2014) 20:664-71. doi: 10.1111/1469-0691.12412

145. Kinker GS, Vitiello GAF, Ferreira WAS, Chaves AS, Cordeiro de Lima VC, Medina TDS. B Cell Orchestration of Anti-Tumor Immune Responses: A Matter of Cell Localization and Communication. Front Cell Dev Biol (2021) 9:678127. doi: $10.3389 /$ fcell.2021.678127

146. Tomczak K, Czerwińska P, Wiznerowicz M. The Cancer Genome Atlas (TCGA): An Immeasurable Source of Knowledge. Wspolczesna Onkol (2015) 1A:A68-77. doi: 10.5114/wo.2014.47136

147. Varn FS, Schaafsma E, Wang Y, Cheng C. Genomic Characterization of Six Virus-Associated Cancers Identifies Changes in the Tumor Immune Microenvironment and Altered Genetic Programs. Cancer Res (2018) 78:6413-23. doi: 10.1158/0008-5472.CAN-18-1342

148. Cao S, Wylie KM, Wyczalkowski MA, Karpova A, Ley J, Sun S, et al. Dynamic Host Immune Response in Virus-Associated Cancers. Commun Biol (2019) 2:109. doi: 10.1038/s42003-019-0352-3

149. de Fátima Aquino Moreira-Nunes C, de Souza Almeida Titan Martins CN, Feio D, Lima IK, Lamarao LM, de Souza CRT, et al. PD-L1 Expression Associated With Epstein-Barr Virus Status and Patients' Survival in a Large Cohort of Gastric Cancer Patients in Northern Brazil. Cancers (Basel) (2021) 13:3107. doi: 10.3390/cancers13133107

150. Nakano H, Saito M, Nakajima S, Saito K, Nakayama Y, Kase K, et al. PD-L1 Overexpression in EBV-Positive Gastric Cancer is Caused by Unique Genomic or Epigenomic Mechanisms. Sci Rep (2021) 11:1982. doi: 10.1038/s41598-021-81667-w

151. Zhang M, Hu S, Min M, Ni Y, Lu Z, Sun X, et al. Dissecting Transcriptional Heterogeneity in Primary Gastric Adenocarcinoma by Single Cell RNA Sequencing. Gut (2021) 70:464-75. doi: 10.1136/gutjnl-2019-320368

152. Jing L, Ott M, Church CD, Kulikauskas RM, Ibrani D, Iyer JG, et al. Prevalent and Diverse Intratumoral Oncoprotein-Specific CD8 + T Cells Within Polyomavirus-Driven Merkel Cell Carcinomas. Cancer Immunol Res (2020) 8:648-59. doi: 10.1158/2326-6066.CIR-19-0647

153. Piersma SJ, Welters MJP, van der Hulst JM, Kloth JN, Kwappenberg KM, Trimbos BJ, et al. Human Papilloma Virus Specific T Cells Infiltrating Cervical Cancer and Draining Lymph Nodes Show Remarkably Frequent Use of HLA-DQ and -DP as a Restriction Element. Int J Cancer (2008) 122:486-94. doi: 10.1002/ijc.23162

154. van Poelgeest MIE, Visconti VV, Aghai Z, van Ham VJ, Heusinkveld M, Zandvliet ML, et al. Potential Use of Lymph Node-Derived HPV-Specific T Cells for Adoptive Cell Therapy of Cervical Cancer. Cancer Immunol Immunother (2016) 65:1451-63. doi: 10.1007/s00262-016-1892-8

155. Albers A, Abe K, Hunt J, Wang J, Lopez-Albaitero A, Schaefer C, et al. Antitumor Activity of Human Papillomavirus Type 16 E7-Specific T Cells Against Virally Infected Squamous Cell Carcinoma of the Head and Neck. Cancer Res (2005) 65:11146-55. doi: 10.1158/0008-5472.CAN-05-0772

156. Bhatt KH, Neller MA, Srihari S, Crooks P, Lekieffre L, Aftab BT, et al. Profiling HPV-16-Specific T Cell Responses Reveals Broad Antigen Reactivities in Oropharyngeal Cancer Patients. J Exp Med (2020) 217: e20200389. doi: 10.1084/jem.20200389

157. Eberhardt CS, Kissick HT, Patel MR, Cardenas MA, Prokhnevska N, Obeng RC, et al. Functional HPV-Specific PD-1 + Stem-Like CD8 T Cells in Head and Neck Cancer. Nature (2021) 597:279-84. doi: 10.1038/s41586-02103862-z

158. Hoffmann TK, Arsov C, Schirlau K, Bas M, Friebe-Hoffmann U, Klussmann JP, et al. T Cells Specific for HPV16 E7 Epitopes in Patients With Squamous Cell Carcinoma of the Oropharynx. Int J Cancer (2006) 118:1984-91. doi: 10.1002/ijc.21565

159. Chua D, Huang J, Zheng B, Lau SY, Luk W, Kwong DL, et al. Adoptive Transfer of Autologous Epstein-Barr Virus-Specific Cytotoxic T Cells for Nasopharyngeal Carcinoma. Int J Cancer (2001) 94:73-80. doi: 10.1002/ ijc. 1430

160. Straathof KCM, Bollard C, Popat U, Huls MH, Lopez T, Morriss MC, et al. Treatment of Nasopharyngeal Carcinoma With Epstein-Barr Virus-Specific 
T Lymphocytes. Blood (2005) 105:1898-904. doi: 10.1182/blood-2004-072975

161. Kuzushima K, Nakamura S, Nakamura T, Yamamura Y, Yokoyama N, Fujita $\mathrm{M}$, et al. Increased Frequency of Antigen-Specific CD8+ Cytotoxic T Lymphocytes Infiltrating an Epstein-Barr Virus-Associated Gastric Carcinoma. J Clin Invest (1999) 104:163-71. doi: 10.1172/JCI6062

162. Li FJ, Zhang Y, Jin GX, Yao L, Wu DQ. Expression of LAG-3 is Coincident With the Impaired Effector Function of HBV-Specific CD8+ T Cell in HCC Patients. Immunol Lett (2013) 150:116-22. doi: 10.1016/j.imlet.2012.12.004

163. Di Donato V, Caruso G, Petrillo M, Kontopantelis E, Palaia I, Perniola G, et al. Adjuvant HPV Vaccination to Prevent Recurrent Cervical Dysplasia After Surgical Treatment: A Meta-Analysis. Vaccines (2021) 9:410. doi: 10.3390 /vaccines 9050410

164. Ghelardi A, Parazzini F, Martella F, Pieralli A, Bay P, Tonetti A, et al. SPERANZA Project: HPV Vaccination After Treatment for CIN2+. Gynecol Oncol (2018) 151:229-34. doi: 10.1016/j.ygyno.2018.08.033

165. Draper LM, Kwong MLM, Gros A, Stevanovic S, Tran E, Kerkar S, et al. Targeting of HPV-16+ Epithelial Cancer Cells by TCR Gene Engineered T Cells Directed Against E6. Clin Cancer Res (2015) 21:4431-9. doi: 10.1158/ 1078-0432.CCR-14-3341

166. Koh S, Shimasaki N, Suwanarusk R, Ho ZZ, Chia A, Banu N, et al. A Practical Approach to Immunotherapy of Hepatocellular Carcinoma Using T Cells Redirected Against Hepatitis B Virus. Mol Ther Nucleic Acids (2013) 2:e114. doi: 10.1038/mtna.2013.43

167. Sharma S, Leung WK, Heslop HE. Virus-Specific T Cells for the Treatment of Malignancies-Then, Now, and the Future. Curr Stem Cell Rep (2020) 6:17-29. doi: 10.1007/s40778-020-00170-6

168. Strickley JD, Messerschmidt JL, Awad ME, Li T, Hasegawa T, Ha DT, et al. Immunity to Commensal Papillomaviruses Protects Against Skin Cancer. Nature (2019) 575:519-22. doi: 10.1038/s41586-019-1719-9

169. Erkes DA, Smith CJ, Wilski NA, Caldeira-Dantas S, Mohgbeli T, Snyder CM, et al. Virus-Specific CD8 + T Cells Infiltrate Melanoma Lesions and Retain Function Independently of PD-1 Expression. J Immunol (2021) 198(7):297988. doi: $10.4049 /$ jimmunol.1601064

170. Simoni Y, Becht E, Fehlings M, Loh CY, Koo SL, Teng KWW, et al. Bystander CD8+ T Cells are Abundant and Phenotypically Distinct in Human Tumour Infiltrates. Nature (2018) 557:575-9. doi: 10.1038/s41586018-0130-2

171. Rosato PC, Wijeyesinghe S, Stolley JM, Nelson CE, Davis RL, Manlove LS, et al. Virus-Specific Memory T Cells Populate Tumors and can be Repurposed for Tumor Immunotherapy. Nat Commun (2019) 10:567. doi: 10.1038/s41467-019-08534-1

172. Maurice NJ, McElrath MJ, Andersen-Nissen E, Frahm N, Prlic M, et al. CXCR3 Enables Recruitment and Site-Specific Bystander Activation of Memory CD8+ T Cells. Nat Commun (2019) 10:1-15. doi: 10.1038/ s41467-019-12980-2

173. Tough DF, Borrow P, Sprent J. Induction of Bystander T Cell Proliferation by Viruses and Type I Interferon in Vivo. Science (1996) 80- ) 272:1947-50. doi: $10.1126 /$ science. 272.5270 .1947

174. Tietze JK, Wilkins DEC, Sckisel GD, Bouchlaka MN, Alderson KL, Weiss JM, et al. Delineation of Antigen-Specific and Antigen-Nonspecific CD8+ Memory T-Cell Responses After Cytokine-Based Cancer Immunotherapy. Blood (2012) 119:3073-83. doi: 10.1182/blood-2011-07-369736

175. Monjazeb AM, Tietze JK, Grossenbacher SK, Hsiao HH, Zamora AE, Mirsoian A, et al. Bystander Activation and Anti-Tumor Effects of CD8+ T Cells Following Interleukin-2 Based Immunotherapy is Independent of CD4+ T Cell Help. PloS One (2014) 9:e102709. doi: 10.1371/ journal.pone.0102709

176. Danahy DB, Berton RR, Badovinac VP. Cutting Edge: Antitumor Immunity by Pathogen-Specific CD8 T Cells in the Absence of Cognate Antigen Recognition. J Immunol (2020) 204:1431-5. doi: 10.4049/jimmunol.1901172

177. Newman JH, Chesson CB, Herzog NL, Bommareddy PK, Aspromonte SM, Pepe R, et al. Intratumoral Injection of the Seasonal Flu Shot Converts Immunologically Cold Tumors to Hot and Serves as an Immunotherapy for Cancer. Proc Natl Acad Sci (2020) 117(2):1119-28. doi: 10.1073/pnas. 1904022116

178. Kohlhapp FJ, Huelsmann EJ, Lacek AT, Schenkel JM, Lusciks J, Broucek JR, et al. Non-Oncogenic Acute Viral Infections Disrupt Anti- Cancer Responses and Lead to Accelerated Cancer- Specific Host Death Report NonOncogenic Acute Viral Infections Disrupt Anti-Cancer Responses and Lead to Accelerated Cancer-Specific Host Death. Cell Rep (2016) 17 (4):957-65. doi: 10.1016/j.celrep.2016.09.068

179. Grandi N, Tramontano E. Human Endogenous Retroviruses are Ancient Acquired Elements Still Shaping Innate Immune Responses. Front Immunol (2018) 9:2039. doi: 10.3389/fimmu.2018.02039

180. Kassiotis G, Stoye JP. Making a Virtue of Necessity: The Pleiotropic Role of Human Endogenous Retroviruses in Cancer. Philos Trans R Soc B Biol Sci (2017) 372:20160277. doi: $10.1098 /$ rstb.2016.0277

181. Hurst TP, Magiorkinis G. Activation of the Innate Immune Response by Endogenous Retroviruses. J Gen Virol (2015) 96:1207-18. doi: 10.1099/ jgv.0.000017

182. Smith CC, Beckermann KE, Bortone DS, De Cubas AA, Bixby LM, Lee SJ, et al. Endogenous Retroviral Signatures Predict Immunotherapy Response in Clear Cell Renal Cell Carcinoma. J Clin Invest (2018) 128:4804-20. doi: $10.1172 / J C I 121476$

183. Goel S, Decristo MJ, Watt AC, BrinJones H, Sceneay J, Li BB, et al. CDK4/6 Inhibition Triggers Anti-Tumour Immunity. Nature (2017) 548:471-5. doi: 10.1038/nature23465

184. Leruste A, Tosello J, Ramos RN, Tauziede-Espariat A, Brohard S, Han ZY, et al. Clonally Expanded T Cells Reveal Immunogenicity of Rhabdoid Tumors. Cancer Cell (2019) 36:597-612.e8. doi: 10.1016/j.ccell.2019.10.008

185. Jansz N. DNA Methylation Dynamics at Transposable Elements in Mammals. Essays Biochem (2019) 63:677-89. doi: 10.1042/EBC20190039

186. Zamudio N, Bourc'his D. Transposable Elements in the Mammalian Germline: A Comfortable Niche or a Deadly Trap? Heredity (Edinb) (2010) 105:92-104. doi: 10.1038/hdy.2010.53

187. Chen R, Ishak CA, De Carvalho DD. Endogenous Retroelements and the Viral Mimicry Response in Cancer Therapy and Cellular Homeostasis. Cancer Discov (2021) 11:2707-25. doi: 10.1158/2159-8290.CD-21-0506

188. Ohtani H, Liu M, Zhou W, Liang G, Jones PA. Switching Roles for DNA and Histone Methylation Depend on Evolutionary Ages of Human Endogenous Retroviruses. Genome Res (2018) 28(8):1-11. doi: 10.1101/gr.234229.118

189. Zhao Y, Oreskovic E, Zhang Q, Lu Q, Gilman A, Lin YS, et al. TransposonTriggered Innate Immune Response Confers Cancer Resistance to the Blind Mole Rat. Nat Immunol (2021) 22:1219-30. doi: 10.1038/s41590-021-01027-8

190. Dunn CA, Romanish MT, Gutierrez LE, van de Lagemaat LN, Mager DL. Transcription of Two Human Genes From a Bidirectional Endogenous Retrovirus Promoter. Gene (2006) 366:335-42. doi: 10.1016/j.gene.2005. 09.003

191. Chiappinelli KB, Strissel PL, Desrichard A, Li H, Henke C, Akman B, et al. Inhibiting DNA Methylation Causes an Interferon Response in Cancer via dsRNA Including Endogenous Retroviruses. Cell (2015) 162:974-86. doi: 10.1016/j.cell.2015.07.011

192. Daskalakis M, Brocks D, Sheng YH, Islam MS, Ressnerova A, Assenov Y, et al. Reactivation of Endogenous Retroviral Elements via Treatment With DNMT- and HDAC-Inhibitors. Cell Cycle (2018) 17:811-22. doi: 10.1080/ 15384101.2018.1442623

193. Roulois D, Loo Yau H, Singhania R, Wang Y, Danesh A, Shen SY, et al. DNA-Demethylating Agents Target Colorectal Cancer Cells by Inducing Viral Mimicry by Endogenous Transcripts. Cell (2015) 162:961-73. doi: 10.1016/j.cell.2015.07.056

194. Mehdipour P, Marhon SA, Ettayebi I, Chakravarthy A, Hosseini A, Wang Y, et al. Epigenetic Therapy Induces Transcription of Inverted SINEs and ADAR1 Dependency. Nature (2020) 588:169-73. doi: 10.1038/s41586-0202844-1

195. Cherkasova E, Malinzak E, Rao S, Takahashi Y, Senchenko VN, Kudryavtseva AV, et al. Inactivation of the Von Hippel-Lindau Tumor Suppressor Leads to Selective Expression of a Human Endogenous Retrovirus in Kidney Cancer. Oncogene (2011) 30:4697-706. doi: 10.1038/ onc.2011.179

196. Cherkasova E, Scrivani C, Doh S, Weisman Q, Takahashi Y, Harashima N, et al. Detection of an Immunogenic HERV-E Envelope With Selective Expression in Clear Cell Kidney Cancer. Cancer Res (2016) 76:2177-85. doi: 10.1158/0008-5472.CAN-15-3139

197. Takahashi Y, Harashima N, Kajigaya S, Yokoyama H, Cherkasova E, McCoy JP, et al. Regression of Human Kidney Cancer Following Allogeneic Stem 
Cell Transplantation is Associated With Recognition of an HERV-E Antigen by T Cells. J Clin Invest (2008) 118(3):1099-109. doi: 10.1172/JCI34409

198. Panda A, de Cubas AA, Stein M, Riedlinger G, Kra J, Mayer T, et al. Endogenous Retrovirus Expression is Associated With Response to Immune Checkpoint Blockade in Clear Cell Renal Cell Carcinoma. JCI Insight (2018) 3:e121522. doi: 10.1172/jci.insight.121522

199. Laumont CM, Vincent K, Hesnard L, Audemard E, Bonneil E, Laverdure JP, et al. Noncoding Regions are the Main Source of Targetable Tumor-Specific Antigens. Sci Transl Med (2018) 10:eaau5516. doi: 10.1126/scitranslmed. aau5516

200. Attig J, Young GR, Hosie L, Perkins D, Encheva-Yokoya V, Stoye JP, et al. LTR Retroelement Expansion of the Human Cancer Transcriptome and Immunopeptidome Revealed by De Novo Transcript Assembly. Genome Res (2019) 29(10):1578-90. doi: 10.1101/gr.248922.119

201. Schiavetti F, Thonnard J, Colau D, Boon T, Coulie PG. A Human Endogenous Retroviral Sequence Encoding an Antigen Recognized on Melanoma by Cytolytic T Lymphocytes. Cancer Res (2002) 62:5510-6.

202. Rycaj K, Plummer JB, Yin B, Li M, Garza J, Radvanyi L, et al. Cytotoxicity of Human Endogenous Retrovirus K-Specific T Cells Toward Autologous Ovarian Cancer Cells. Clin Cancer Res (2015) 21:471-83. doi: 10.1158/ 1078-0432.CCR-14-0388

203. Saini SK, Orskov AD, Bjerregaard AM, Unnikrishnan A, Holmberg-Thyden S, Borch A, et al. Human Endogenous Retroviruses Form a Reservoir of T Cell Targets in Hematological Cancers. Nat Commun (2020) 11:1-14. doi: 10.1038/s41467-020-19464-8

204. Chong C, Müller M, Pak HS, Harnett D, Huber F, Grun D, et al. Integrated Proteogenomic Deep Sequencing and Analytics Accurately Identify nonCanonical Peptides in Tumor Immunopeptidomes. Nat Commun (2020) 11:1293. doi: 10.1038/s41467-020-14968-9

205. Ishak CA, De Carvalho DD. Reactivation of Endogenous Retroelements in Cancer Development and Therapy. Annu Rev Cancer Biol (2020) 4:159-76. doi: 10.1146/annurev-cancerbio-030419-033525

206. Loo Yau H, Ettayebi I, De Carvalho DD. The Cancer Epigenome: Exploiting Its Vulnerabilities for Immunotherapy. Trends Cell Biol (2019) 29:31-43. doi: 10.1016/j.tcb.2018.07.006

207. Topper MJ, Vaz M, Marrone KA, Brahmer JR, Baylin SB. The Emerging Role of Epigenetic Therapeutics in Immuno-Oncology. Nat Rev Clin Oncol (2020) 17:75-90. doi: 10.1038/s41571-019-0266-5

208. Martínez-Vélez N, Xipell E, Vera B, Acanda de la Rocha A, Zalacain M, Marrodan L, et al. The Oncolytic Adenovirus VCN-01 as Therapeutic Approach Against Pediatric Osteosarcoma. Clin Cancer Res (2016) 22:2217-25. doi: 10.1158/1078-0432.CCR-15-1899

209. Oku M, Ishino R, Uchida S, Imataki O, Sugimoto N, Todo T, et al. Oncolytic Herpes Simplex Virus Type 1 (HSV-1) in Combination With Lenalidomide for Plasma Cell Neoplasms. Br J Haematol (2021) 192:343-53. doi: 10.1111/ bjh. 17173

210. Reddy PS, Burroughs KD, Hales LM, Ganesh S, Jones BH, Idamakanti N, et al. Seneca Valley Virus, a Systemically Deliverable Oncolytic Picornavirus, and the Treatment of Neuroendocrine Cancers. JNCI J Natl Cancer Inst (2007) 99:1623-33. doi: 10.1093/jnci/djm198

211. Samson A, Scott KJ, Taggart D, West EJ, Wilson E, Nuovo GJ, et al. Intravenous Delivery of Oncolytic Reovirus to Brain Tumor Patients Immunologically Primes for Subsequent Checkpoint Blockade. Sci Transl Med (2018) 10:eaam7577. doi: 10.1126/scitranslmed.aam7577

212. Antoniou E, Orovou E, Sarella A, Iliadou M, Rigas N, Palaska E, et al. Zika Virus and the Risk of Developing Microcephaly in Infants: A Systematic Review. Int J Environ Res Public Health (2020) 17:3806. doi: 10.3390/ ijerph 17113806

213. Ferreira RO, Granha I, Ferreira RS, Bueno HS, Okamoto OK, Kaid C, et al. Effect of Serial Systemic and Intratumoral Injections of Oncolytic ZIKVBR in Mice Bearing Embryonal CNS Tumors. Viruses (2021) 13:2103. doi: 10.3390/ v13102103

214. Kaid C, Goulart E, Caires-Júnior LC, Araujo BHS, Soares-Schanoski A, Bueno HMS, et al. Zika Virus Selectively Kills Aggressive Human Embryonal CNS Tumor Cells In Vitro and In Vivo. Cancer Res (2018) 78:3363-74. doi: 10.1158/0008-5472.CAN-17-3201

215. Kaid C, Madi RA dos S, Astray R, Goulart E, Caires-Junior LC, Mitsugi TG, et al. Safety, Tumor Reduction, and Clinical Impact of Zika Virus Injection in
Dogs With Advanced-Stage Brain Tumors. Mol Ther (2020) 28:1276-86. doi: 10.1016/j.ymthe.2020.03.004

216. Nair S, Mazzoccoli L, Jash A, Govero J, Bais SS, Hu T, et al. Zika Virus Oncolytic Activity Requires CD8+ T Cells and is Boosted by Immune Checkpoint Blockade. JCI Insight (2021) 6:e144619. doi: 10.1172/ jci.insight.144619

217. Andtbacka RHI, Kaufman HL, Collichio F, Amatruda T, Senzer N, Chesney J, et al. Talimogene Laherparepvec Improves Durable Response Rate in Patients With Advanced Melanoma. J Clin Oncol (2015) 33:2780-8. doi: 10.1200/JCO.2014.58.3377

218. Dillman RO, Wiemann MC, Tai DF, Depriest CB, Soori G, Stark JJ, et al. Phase II Trial of Subcutaneous Interferon Followed by Intravenous Hybrid Bolus/Continuous Infusion Interleukin-2 in the Treatment of Renal Cell Carcinoma: Final Results of Cancer Biotherapy Research Group 95-09. Cancer Biother Radiopharm (2006) 21:130-7. doi: 10.1089/cbr.2006.21.130

219. Minasian LM, Motzer RJ, Gluck L, Mazumdar M, Vlamis V, Krown SE. Interferon Alfa-2a in Advanced Renal Cell Carcinoma: Treatment Results and Survival in 159 Patients With Long-Term Follow-Up. J Clin Oncol (1993) 11:1368-75. doi: 10.1200/JCO.1993.11.7.1368

220. Negrier S, Escudier B, Lasset C, Douillard JY, Savary J, Chevreau C, et al. Recombinant Human Interleukin-2, Recombinant Human Interferon Alfa2a, or Both in Metastatic Renal-Cell Carcinoma. N Engl J Med (1998) 338:1272-8. doi: 10.1056/NEJM199804303381805

221. Ascierto PA, Daponte A, Parasole R, Perrone F, Caraco C, Melucci M, et al. Intermediate Dose Recombinant Interferon-Alpha as Second-Line Treatment for Patients With Recurrent Cutaneous Melanoma Who Were Pretreated With Low Dose Interferon. Cancer (2000) 89:1490-4. doi: 10.1002/1097-0142(20001001)89:7<1490::aid-cncr11>3.0.co;2-v

222. Bottomley A, Coens C, Suciu S, Santinami M, Kruit W, Testori A, et al. Adjuvant Therapy With Pegylated Interferon Alfa-2b Versus Observation in Resected Stage III Melanoma: A Phase III Randomized Controlled Trial of Health-Related Quality of Life and Symptoms by the European Organisation for Research and Treatment of Cancer. J Clin Oncol (2009) 27:2916-23. doi: 10.1200/JCO.2008.20.2069

223. Neefe JR, Legha SS, Markowitz A, Salmon S, Meyskens F, Groopman J, et al. Phase II Study of Recombinant $\alpha$-Interferon in Malignant Melanoma. Am J Clin Oncol (1990) 13:472-6. doi: 10.1097/00000421-199012000-00004

224. Rusciani L, Petraglia S, Alotto M, Calvieri S, Vezzoni G. Postsurgical Adjuvant Therapy for Melanoma. Evaluation of a 3-Year Randomized Trial With Recombinant Interferon-Alpha After 3 and 5 Years of FollowUp. Cancer (1997) 79:2354-60. doi: 10.1002/(sici)1097-0142(19970615) 79:12<2354::aid-cncr9>3.0.co;2-1

225. Bosly A, Grigg A, Holte H, Gisselbrecht C, Radford J, Rossi A, et al. A Randomized Study of Interferon $\alpha-2 b$ Versus No Treatment as Consolidation After High Dose Therapy and Autologous Stem Cell Transplantation for Patients With Relapsed Lymphoma. Oncologist (2013) 18:1189-9. doi: 10.1634/theoncologist.2013-0223

226. Opalka B, Wandl UB, Becher R, Kloke O, Nagel-Hiemke M, Moritz T, et al. Minimal Residual Disease in Patients With Chronic Myelogenous Leukemia Undergoing Long-Term Treatment With Recombinant Interferon Alpha- $2 \mathrm{~b}$ Alone or in Combination With Interferon Gamma. Blood (1991) 78:218893. doi: 10.1182/blood.V78.9.2188.bloodjournal7892188

227. Mandelli F, Avvisati G, Amadori S, Boccadoro M, Gernone A, Lauta VM, et al. Maintenance Treatment With Recombinant Interferon Alfa-2b in Patients With Multiple Myeloma Responding to Conventional Induction Chemotherapy. N Engl J Med (1990) 322:1430-4. doi: 10.1056/ NEJM199005173222005

228. Lara PN Jr, Douillard JY, Nakagawa K, von Pawel J, McKeage MJ, Albert I, et al. Randomized Phase III Placebo-Controlled Trial of Carboplatin and Paclitaxel With or Without the Vascular Disrupting Agent Vadimezan (ASA404) in Advanced Non-Small-Cell Lung Cancer. J Clin Oncol (2011) 29:2965-71. doi: 10.1200/JCO.2011.35.0660

229. Shih AY, Damm-Ganamet KL, Mirzadegan T. Dynamic Structural Differences Between Human and Mouse STING Lead to Differing Sensitivity to DMXAA. Biophys J (2018) 114:32-9. doi: 10.1016/ j.bpj.2017.10.027

230. Shekarian T, Valsesia-Wittmann S, Brody J, Michallet MC, Depil S, Caux C, et al. Pattern Recognition Receptors: Immune Targets to Enhance Cancer 
Immunotherapy. Ann Oncol Off J Eur Soc Med Oncol (2019) 30:2017. doi: $10.1093 /$ annonc/mdz225

231. Liu M, Thomas SL, DeWitt AK, Zhou W, Madaj ZB, Ohtani H, et al. Dual Inhibition of DNA and Histone Methyltransferases Increases Viral Mimicry in Ovarian Cancer Cells. Cancer Res (2018) 78(20):5754-66. doi: 10.1158/ 0008-5472.CAN-17-3953

232. Kim K, Skora AD, Li Z, Liu Q, Tam AJ, Blosser RL, et al. Eradication of Metastatic Mouse Cancers Resistant to Immune Checkpoint Blockade by Suppression of Myeloid-Derived Cells. Proc Natl Acad Sci (2014) 111:117749. doi: 10.1073/pnas.1410626111

233. Loo Yau H, Bell E, Ettayebi I, de Almeida FC, Boukhaled GM, Shen SY, et al. DNA Hypomethylating Agents Increase Activation and Cytolytic Activity of CD8+ T Cells. Mol Cell (2021) 81:1469-83.e8. doi: 10.1016/j.molcel. 2021.01.038

234. Jones PA, Ohtani H, Chakravarthy A, De Carvalho DD. Epigenetic Therapy in Immune-Oncology. Nat Rev Cancer (2019) 19:151-61. doi: 10.1038/ s41568-019-0109-9
Conflict of Interest: The authors declare that the research was conducted in the absence of any commercial or financial relationships that could be construed as a potential conflict of interest.

Publisher's Note: All claims expressed in this article are solely those of the authors and do not necessarily represent those of their affiliated organizations, or those of the publisher, the editors and the reviewers. Any product that may be evaluated in this article, or claim that may be made by its manufacturer, is not guaranteed or endorsed by the publisher.

Copyright (๑) 2021 Vitiello, Ferreira, Cordeiro de Lima and Medina. This is an openaccess article distributed under the terms of the Creative Commons Attribution License (CC BY). The use, distribution or reproduction in other forums is permitted, provided the original author(s) and the copyright owner(s) are credited and that the original publication in this journal is cited, in accordance with accepted academic practice. No use, distribution or reproduction is permitted which does not comply with these terms. 